\title{
Cambio climático, riesgos naturales y tecnológicos en el contexto de los modelos de desarrollo
}

\author{
José Antonio Sotelo NAVALPOTRO ${ }^{1}$ \\ Instituto Universitario de Ciencias Ambientales (UCM) \\ jasotelo@ghis.ucm.es
}

Recibido: 26 de junio de 2012

Enviado a evaluar: 29 de junio de 2012

Aceptado: 27 de julio de 2012

\section{RESUMEN}

El cambio climático es una verdadera realidad siempre que lo entendamos como la crisis por la que está pasando el clima de nuestro planeta, especialmente acusada a partir de mediados del pasado siglo. Las fluctuaciones naturales de concentración de anhídrido carbónico y las oscilaciones de los parámetros orbitales del planeta han sido amplificadas por el sistema de corrientes oceánicas y la secuencia de zonas heladas y deshielos en la región circumpolar ártica. Así, se considera que los sumideros de carbono son una solución para mitigar los efectos de cambio climático. Las presiones que el cambio climático puede generar en los ecosistemas (terrestres, acuáticos,...), supone una importante presión adicional sobre los ecosistemas terrestres, afectados ya seriamente en la actualidad por la contaminación, la sobreexplotación y la fragmentación del territorio. Por último, nos detendremos en el análisis de la realidad española.

Palabras clave: Cambio climático, riesgos naturales, riesgos tecnológicos, modelos de desarrollo.

\section{Climate change, natural and technology hazards in the context of development model}

\begin{abstract}
Climate change is a true reality as long as we understand the crisis that is happening on our planet's climate, particularly marked from the middle of last century. Natural fluctuations in carbon dioxide concentration and the oscillations of the orbital planet's parameters have been amplified by the system of ocean currents and the sequence of freezing and thawing areas in the circumpolar Arctic. Thus, it is considered that carbon sinks are a solution to mitigate the effects of climate change. The pressures that climate change can result
\end{abstract}

\footnotetext{
${ }^{1}$ IUCA. Grupo de Investigación UCM: Desarrollo y Gestión Ambiental del Territorio. UCM. PROYECTO CICYT. CGL2007-63779
} 
in ecosystems (land, water,...), is a significant additional pressure on terrestrial ecosystems, already seriously affected today by pollution, overexploitation and land fragmentation. Finally, we stop at the analysis of the Spanish reality.

Keywords: Climate change, natural hazards, technological hazards, development models.

\section{Changement climatique, risques naturels et technologiques dans le contexte des modèles de développement}

\section{RÉSUMÉ}

Le changement climatique est une vraie réalité, s'il est compris en tant que crise qui traverse le climat de notre planète, accusée, notamment, à partir du milieu du siècle dernier. Les fluctuations naturelles des concentrations de dioxyde de carbone et les oscillations des paramètres orbitaux de la planète ont été amplifiées par le système de courants océaniques et par les cycles des gel- dégel de la région circumpolaire arctique. On estime ainsi, que les puits de carbone représentent une solution permettant d'atténuer les effets du changement climatique. Les pressions que le changement climatique peut provoquer dans les écosystèmes (terrestres, aquatiques,...), constitue une importante pression supplémentaire entraînée sur les écosystèmes terrestres, déjá gravement affectés, actuellement, par la pollution, la sureexplotation et la fragmentation du territoire. Enfin, nous nous attarderons sur l'analyse de la réalité espagñole.

Mots clé: Changement climatique, risques naturels, risques technologiques, modèles de développement.

\section{INTRODUCCIÓN: LA DUALIDAD CLIMA Y CAMBIO CLIMÁTICO}

El clima del planeta Tierra se puede definir como la sucesión temporal de las distintas distribuciones espaciales de la temperatura del aire y la lluvia sobre su superficie. La historia del ser humano ha discurrido durante este último millón de años. Desde entonces el clima ha variado lentamente. Sin embargo, en la actualidad hablamos de cambio climático. ¿Como responderá la sociedad humana a este nuevo escenario? Se pregunta el profesor Antonio Ruíz Elvira (Universidad de Alcalá); es un reto para el planeta en el que interviene, como factor predominante hoy, la especie humana.

El sistema climático está formado por los subsistemas Atmósfera, Océanos, Hielo y Biosfera. Aunque la energía nuclear presenta problemas para su uso en la Tierra, la energía para el movimiento de las partículas que forman los subsistemas climáticos, para el crecimiento de la vegetación y el metabolismo de los seres vivos la proporciona casi en su totalidad un reactor nuclear en modo de fusión que denominamos Sol. Una pequeña parte proviene de las reacciones nucleares que ocurren constantemente en el interior del planeta y que producen los movimientos tectónicos.

La temperatura media global (TMG) del planeta es el promedio anual del promedio de las temperaturas del aire en la superficie de cada punto de la esfera terrestre. 
La TMG ha oscilado en un intervalo de unos 10 grados a lo largo de la historia del planeta. Como cualquier cuerpo físico, el planeta emite constantemente radiación, cuya longitud de onda depende de la temperatura de su superficie. La radiación emitida desde la superficie de la Tierra está en el intervalo del infrarrojo, que puede ser absorbida por algunos de los gases traza de la atmósfera.

Es sabido que la presencia en la atmósfera del planeta de los gases traza anhídrido carbónico, metano y vapor de agua, implica, por un efecto similar al del de las mantas de lana, un aumento de la temperatura del aire en la parte baja de la atmósfera. Una manta de lana retiene, durante un intervalo de tiempo, entre ella y el cuerpo, parte del calor que éste emite al metabolizar los alimentos. Los gases traza retienen, durante un intervalo de tiempo, entre la superficie de la Tierra y la estratosfera, parte de la energía que esa superficie emite hacia el espacio exterior constantemente

Para una misma TMG en distintas etapas geológicas, la temperatura del aire depende de la distribución espacial de las tierras emergidas, los océanos y la circulación del agua en ellos y de la concentración de gases traza en la parte baja de la atmósfera.

La distribución espacio-temporal de la temperatura del aire en el último millón de años ha sido el resultado de la presencia de un océano ártico sin islas, y de la presencia de otros tres océanos, el Atlántico, el Índico-Pacífico y el océano austral. La situación del océano ártico, rodeado de tierra, es equivalente a la de un amplificador no lineal, con dos estados metastables, según una curva del tipo de la Figura 1.

Figura 1. Una curva típica de energía potencial en un sistema con dos estados "metastables": El sistema puede pasar de uno a otro estado de forma rápida y permanecer en cada uno de esos estados durante largo tiempo

Esquema de la funcion potencial hielo - no hielo

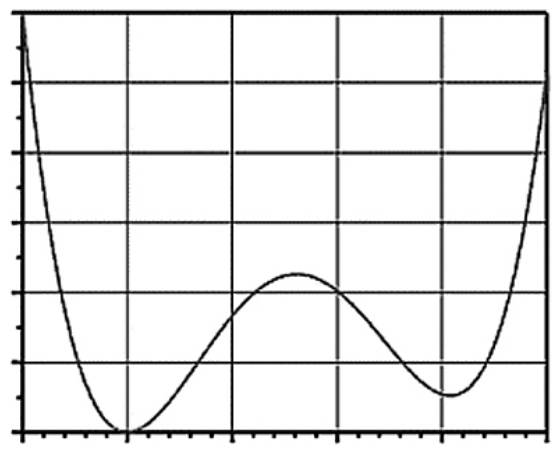

Fuente: Antonio Ruiz Elvira

Las fluctuaciones naturales de concentración de anhídrido carbónico y las oscilaciones de los parámetros orbitales del planeta han sido amplificadas por el sistema de corrientes oceánicas y la secuencia de zonas heladas y deshielos en la región circumpolar ártica.

La historia del ser humano ha discurrido durante este último millón de años, y es probable que muchos de los cambios sociales que adivinamos en los registros tengan 
que ver con las secuencias de glaciaciones, deshielos y periodos interglaciales. Es interesante constatar que el último periodo glacial acabó unos 8000 años antes de la era cristiana. Las leyendas acerca de diluvios quizá tengan algo que ver con esto, y recordemos que una nueva forma de vida social de la especie humana empezó también por aquellas fechas.

Desde entonces el clima ha variado lentamente. Así, en la época romana Siria y el norte de África eran el granero del Mediterráneo. Hoy hablamos de cambio climático. Como el clima es una secuencia temporal, es difícil entender lo que queremos decir por "cambio climático". El clima está cambiando constantemente. Sin embargo lo que estamos detectando en los últimos 100 años es un ritmo de cambio mucho más rápido que los que corresponden a la secuencia temporal registrada para etapas históricas anteriores a la presente, $\mathrm{y}$ en un sentido muy distinto.

El profesor Antonio Ruiz Elvira nos plantea nuevas incertidumbres, a partir de modelos matemáticos de integración por diferencias finitas. Los modelos de las ecuaciones diferenciales no lineales de los cinco sistemas acoplados: aire (como elemento mecano-termodinámico, $\mathrm{y}$, como conjunto de gases que interaccionan con la radiación electromagnética), agua, hielo y biosfera, producen la evolución temporal de las distribuciones espaciales de temperatura y precipitación -el clima- como funciones del tiempo y del espacio (Fig. 2.).; a saber:

Figura 2. De las distribuciones espaciales de temperatura y precipitación como funciones del tiempo y del espacio

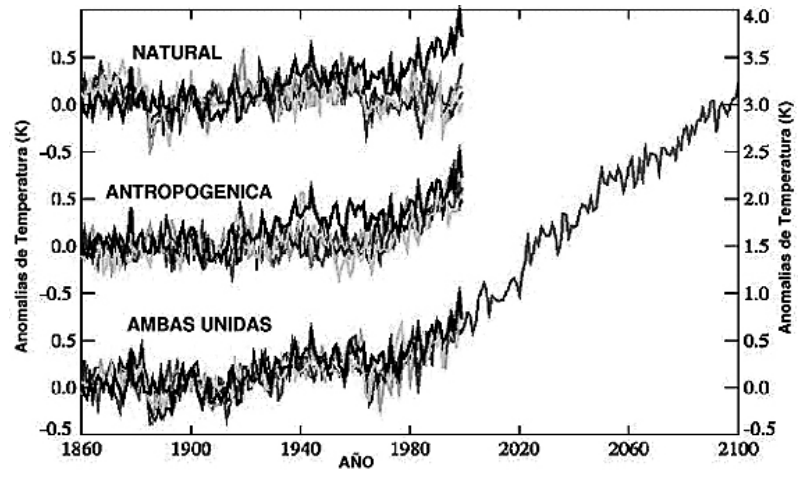

Fuente: Antonio Ruiz Elvira

Aceptemos, pues, que la TMG va a subir unos $4{ }^{\circ} \mathrm{C}$ en unos 200 años, desde 1900 a 2100 , y que esto es debido al aumento de concentración de gases manta en la atmósfera. ¿Plantea esto algún problema para la sociedad humana? La vida sobre la Tierra continuará. Continuará incluso si un cataclismo destruye plantas y animales y deja solo virus. Pero a los humanos realmente lo que nos interesa es nuestra sociedad, nuestra especie.

El ser humano se ha adaptado a toda clase de secuencias temporales de temperatura y precipitación, y vive tanto en los trópicos como en los desiertos calientes y en los desiertos de hielo. Por lo tanto es posible suponer que una subida de la TMG de $4{ }^{\circ} \mathrm{C}$ 
no impedirá la continuación de la existencia de la especie humana. Pero la pregunta no es tanto la continuación de la especie, sino cómo se va a adaptar la especie a las nuevas condiciones. Basta recordar que uno de los problemas más importantes de la humanidad han sido las migraciones masivas, y que estas pueden exagerarse cuando la disponibilidad de agua dulce cambia en el tiempo en las distintas regiones del planeta.

La TMG es un promedio espacial de las temperaturas del planeta. La superficie del planeta va a recibir una cantidad algo mas alta de energía en estos próximos 100 años de la que recibía hace 200 años. La superficie del trópico es esencialmente agua. Al recibir más energía el agua se evapora, manteniendo su temperatura. Sin embargo el hielo a menos de $30{ }^{\circ} \mathrm{C}$ bajo cero aumenta su temperatura desde esos $-30{ }^{\circ} \mathrm{C}$ hasta $0{ }^{\circ} \mathrm{C}$ sin fundirse. Al hacer el promedio para calcular la TMG hay muchos más puntos correspondientes a los trópicos que a los polos porque la superficie de una esfera es mayor entre el Ecuador y $\operatorname{los} 30^{\circ}$ de latitud que entre los $60^{\circ}$ de latitud y cada polo. Puesto que la temperatura en el Ecuador no va a aumentar casi nada, los aumentos serán hacia las zonas polares, y allí la subida de temperatura será mucho mayor que esos $4{ }^{\circ} \mathrm{C}$ de la TMG.

La primera consecuencia del aumento de la TMG será un desplazamiento del sistema de lluvias de las latitudes templadas hacia los polos. Para la Península Ibérica, el resultado del cambio climático es preocupante. La Península Ibérica está en una posición lo suficientemente sureña como para que el chorro produzca lluvias solo durante una parte del año, con etapas de sequía frecuentes. Un desplazamiento hacia el norte de la posición del chorro de unos 1000 kilómetros produciría un aumento notable de las etapas de sequía, puntuadas por episodios intermitentes de lluvias torrenciales.

¿Qué otras consecuencias tendrá el cambio climático? Una de ellas ya la estamos constatando: la desaparición de los glaciares. Los glaciares han disminuido su extensión en todo el globo. Para poner un ejemplo, el glaciar del Monte Perdido en los Pirineos tenía una extensión de 300 Ha hacia 1880 y de unas 3 Ha en el año 2000. Una disminución de los depósitos de nieve en invierno implica que las reservas de agua para el verano sean exclusivamente las de los embalses. Una temperatura más alta, aún siendo de un par de grados, implica una evapotranspiración mayor de suelos y plantas.

En las regiones caribeñas una subida de temperaturas presenta otros riesgos. Una subida de la TMG implicará una mayor humedad relativa del aire. Los huracanes y tifones se amplifican, una vez formados, por condensación del vapor de agua en las columnas ascendentes de aire en el núcleo del huracán. Mayor cantidad de vapor de agua significa huracanes más intensos y mayor oportunidad para el mantenimiento de los que se vayan formando. Adicionalmente, otra de las condiciones para los huracanes es que los vientos en las capas altas de la atmósfera (el chorro) sean débiles o inexistentes en las zonas de huracanes, lo cual también se cumplirá en una situación de cambio climático.

Otro ejemplo lo hemos encontrado a finales de julio del 2012. Cada verano, cerca de la mitad de la superficie de la capa de hielo que cubre Groenlandia suele derretirse. Por eso, cuando el pasado 12 de julio los satélites enviaron sus datos sobre el pro- 
ceso, los científicos de la NASA no daban crédito: el 97\% de la cubierta se había fundido en solo cuatro días. El fenómeno es tan extraordinario - no constan precedentes desde que se registran los datos-, que de hecho pensaron que se trataba de un error. El deshielo se produjo rápidamente. Mapas derivados de tres satélites independientes mostraron que el 8 de julio solo el $40 \%$ de la superficie de la capa de hielo se había derretido. Cuatro días después, casi toda la cubierta, desde las zonas más finas en las costas hasta los dos kilómetros de profundidad en el interior, había experimentado algún grado de fusión en su superficie (ver figura 3)

Figura 3. El deshielo de Groenlandia en el verano de 2012

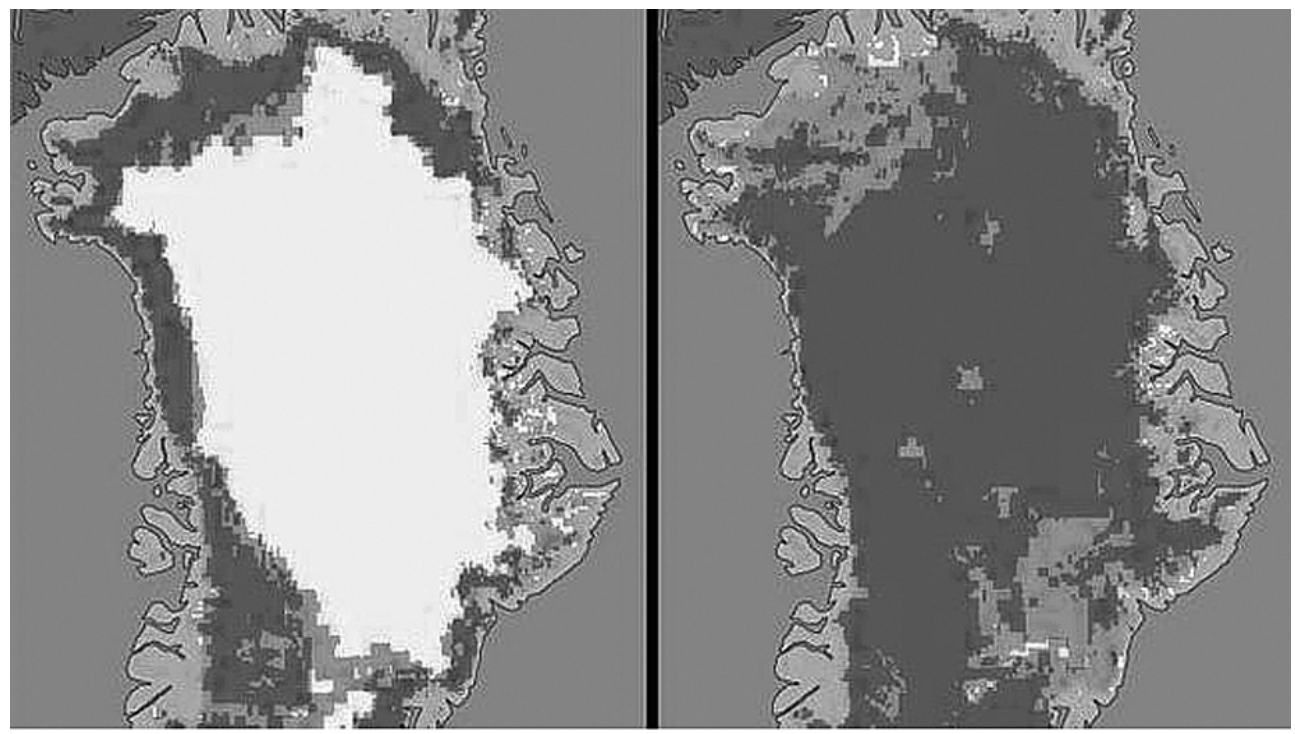

NOTA: Entre el 8 (izq.) y el 12 de julio (dcha.) Groenlandia mostró signos de deshielo en más del 90\% de su superficie

Fuente: NASA. Julio 2012

Los investigadores aún no han determinado si el fenómeno afectará el volumen global de pérdida de hielo este verano y contribuirá a la elevación del nivel del mar. En las zonas altas, la mayor parte del agua de deshielo vuelve a congelarse rápidamente en el mismo lugar. Pero cerca de la costa, la mayoría se pierde en el océano. Se trata del segundo fenómeno inusual que se produce en la isla este verano. La semana pasada, un iceberg gigante que duplicaba en tamaño a la isla de Manhattan se desprendió del glaciar Petermann y quedó a la deriva en el mar. Un hecho que los investigadores no consideraron preocupante por sí solo, pero que, unido al excepcional deshielo, puede ser síntoma de un proceso de cambio. "Las observaciones por satélite están ayudando a entender cómo este tipo de eventos pueden relacionarse unos con otros, así como con su conexión con el sistema climático global", asegura Tom Wagner, director del programa de criosfera de la NASA en Washington (ver figura 4) 
Figura 4. Un iceberg desprendiéndose del glaciar Petermann, al noroeste de Groenlandia

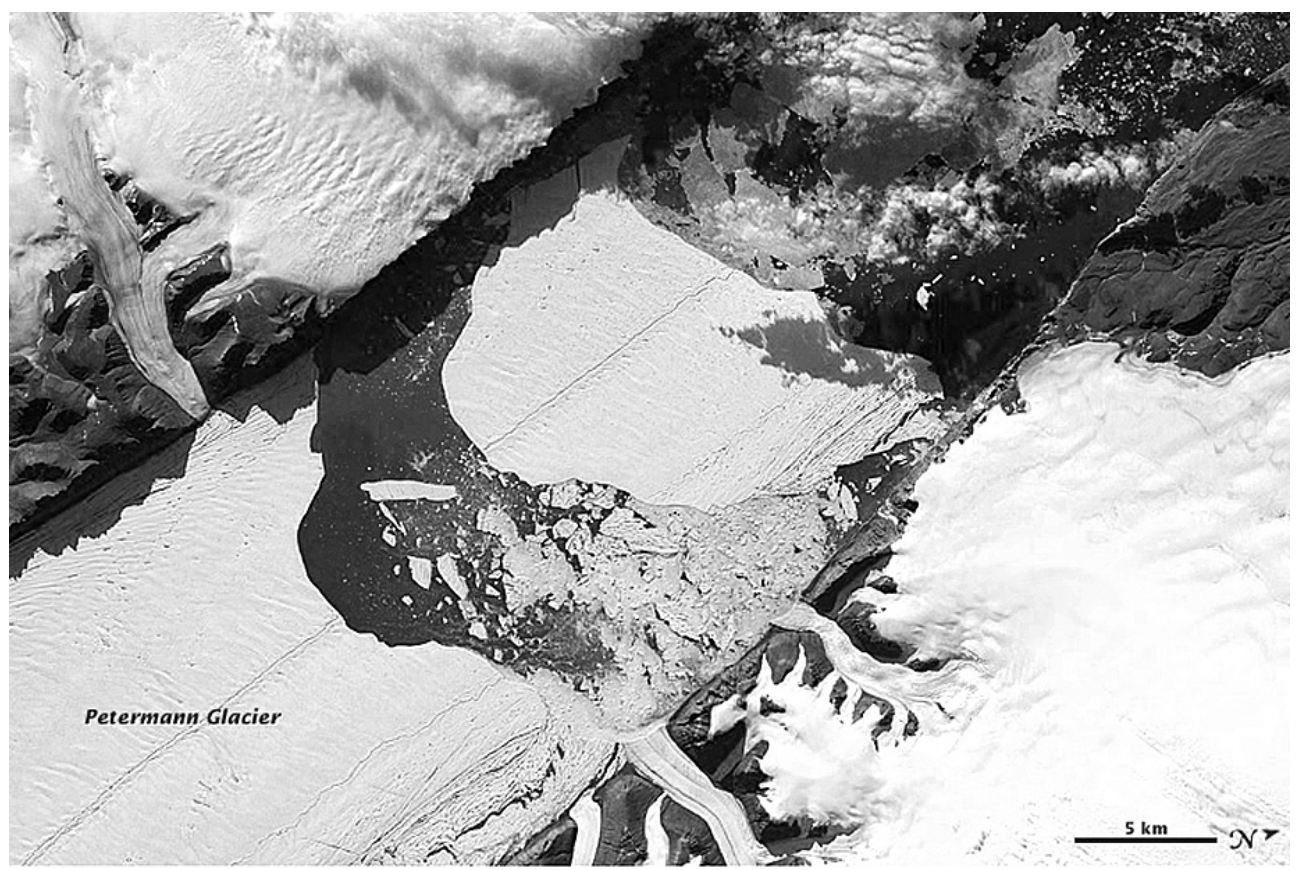

Fuente: NASA, julio del 2012

Durante varios días de este mes, la cobertura de hielo en la superficie de Groenlandia ha sufrido un proceso de fusión en un área mayor que en cualquier momento anterior a lo largo de más de 30 años de observaciones satelitales, según informó este martes la NASA a través de su web. Después de que hace unos días, un iceberg de un tamaño equivalente a dos veces la isla de Manhattan se desprendiese del glaciar de Petermann en Groenlandia (y anteriormente en 2010), la capa de hielo parece derretirse por las altas temperaturas. Casi toda la cubierta de hielo de Groenlandia, desde las zonas más finas en las costas hasta los dos kilómetros de profundidad en el interior, ha experimentado algún grado de fusión en su superficie a mediados de este mes debido a las altas temperaturas, de acuerdo con las mediciones de tres satélites independientes analizadas por científicos de la NASA y universidades. En promedio, durante el verano, cerca de la mitad de la superficie de la capa de hielo de Groenlandia se derrite de forma natural.

En las zonas altas, la mayor parte de esa agua de deshielo rápidamente vuelve a congelarse en el mismo lugar. Cerca de la costa, algo del agua de fusión es retenida por la capa de hielo y el resto se pierde en el océano. Pero este año el grado de fusión del hielo en la superficie ha aumentado notablemente. De acuerdo con los datos de satélite, se estima que el 97 por ciento de la superficie de la capa de hielo se ha descongelado en algún momento a mediados de julio. Los investigadores aún no han 
determinado si este evento extenso de fusión afectará al volumen global de pérdida de hielo este verano y contribuirá a la elevación del nivel del mar.

«La capa de hielo de Groenlandia es una extensa zona con una historia variada de cambio. Este evento, junto con otros fenómenos naturales, aunque poco frecuentes, como el caso de la fractura de un enorme iceberg la semana pasada en el glaciar Petermann, son parte de una historia compleja», dijo Tom Wagner, director del programa de criosfera de la NASA en Washington. «Las observaciones por satélite están ayudando a entender cómo eventos como estos pueden relacionarse unos con otros, así como con el sistema climático más amplio».

Son Nghiem, del Laboratorio de Propulsión a Chorro en Pasadena, California, realizó un primer análisis de datos de radar del satélite Oceansat-2 de la Indian Space Research Organisation (ISRO) la semana pasada, cuando se dio cuenta de que la mayor parte de la superficie de Groenlandia parecía que había sido sometida a una fusión del hielo el 12 de julio. Nghiem dijo: «Esto fue tan extraordinario que en un primer momento me cuestioné el resultado». Nghiem consultó con Dorothy Hall, en el Centro Goddard de Vuelo Espacial en Greenbelt, Maryland, que estudia la temperatura de la superficie de Groenlandia con el Espectrómetro de Imágenes MODIS a bordo de los satélites Terra y Aqua de la NASA. Confirmó que MODIS mostró temperaturas inusualmente altas y que el deshielo era extenso sobre la superficie de la capa de hielo.

Thomas Mote, un climatólogo de la Universidad de Georgia, Athens, Georgia, y Marco Tedesco, de la Universidad de la Ciudad de Nueva York también confirmaron la fusión vista por Oceansat-2 y MODIS a través de imágenes de sensores de microondas en un satélite meteorológico de la Fuerza Aérea de EE.UU. El deshielo se extendió rápidamente. Mapas derivados de los tres satélites mostraron que el 8 de julio alrededor del 40 por ciento de la superficie de la capa de hielo se había derretido. El 12 de julio, el 97 por ciento se había derretido.

Este evento de fusión extrema se ha debido a una cresta inusualmente fuerte de aire caliente, o cúpula de calor, sobre Groenlandia. Este evento ha sido parte de una serie que ha dominado el clima de Groenlandia desde fines de mayo. «Cada cresta sucesiva ha sido más fuerte que el anterior», dijo Mota. Esta cúpula última de calor comenzó a moverse sobre Groenlandia el 8 de julio, y luego se estacionó sobre la capa de hielo unos tres días más tarde. Hacia el 16 de julio había comenzado a disiparse. Incluso el área alrededor de una estación en el centro de Groenlandia, que a 2.000 metros sobre el nivel del mar está cerca del punto más alto de la capa de hielo, mostró signos de fusión. Dicha fusión pronunciada en la en la capa de hielo de la zona no se había producido desde 1889 , de acuerdo con los núcleos de hielo analizados. «Los núcleos de hielo muestran que los eventos de fusión de este tipo ocurren aproximadamente una vez cada 150 años en promedio. Con el último acontecimiento en el año 1889, este evento llega justo a tiempo», dice Lora Koenig, un glaciólogo del centro Goddard y miembro del equipo de análisis de los datos obtenidos por satélite. «Pero si seguimos observando los acontecimientos de este tipo de fusión en los próximos años, será preocupante». 


\section{SUMIDEROS DE CARBÓN: ¿SOLUCIÓN O TÓPICO?}

Como señala el profesor Rosas, se considera que los sumideros de carbono son una solución para mitigar los efectos de cambio climático. Sin embargo, distintos estudios directos o indirectos, demuestran las incertidumbres de esta aparente solución. Existen argumentos en contra de la propuesta de los sumideros que se pueden clasificar en cinco tipos: 1) factores ambientales que afectan a los sumideros, 2) posible ineficacia de los sumideros, 3) limitaciones temporales, 4) efectos perjudiciales de acciones tales como la inyección de $\mathrm{CO} 2$ en los océanos y la plantación masiva de bosques y 5) desconocimiento de los mecanismos responsables del funcionamiento de los sumideros.

No son pocos los estudiosos de estos temas que como Houghton et al. (1999) afirman que la tasa de acumulación de carbono en los ecosistemas terrestres y los mecanismos responsables del funcionamiento de los sumideros son inciertos. Este es el punto más relevante en la discusión en torno a los sumideros, ya que no es posible una solución efectiva sin conocer en qué consiste esa efectividad (Sundquist, 1993; Houghton et al. 1999; Smaglik, 2000). Esta efectividad es, además, condicionada por varios factores entre los cuales se encuentra el propio cambio climático (Cao y Woodward, 1998; Sarmiento et al., 1998; Tian et al., 1998; Schimel et al., 2000). Por ejemplo, el fenómeno del Niño actúa como un control del almacenamiento terrestre de carbono (Keeling et al. 1995). Si el incremento de la temperatura no estimula la tasa de descomposición de carbono en los suelos de los bosques (Giardina y Ryan, 2001), los sumideros continuarían siendo útiles a largo plazo independientemente del calentamiento global. Inclusive, Schimel y colaboradores (2000) encontraron que los efectos del clima y del $\mathrm{CO}_{2}$ en el secuestro de carbono en Estados Unidos son probablemente iguales o menores que los efectos del manejo intensivo de bosques y abandono de la agricultura.

La fertilidad del suelo y el exceso de lluvia también pueden disminuir el secuestro de $\mathrm{CO}_{2}$ (Oren et alii., 2001; Sarmiento et al. 1998). Estos factores pueden estar determinando la ineficiencia de los sumideros e implicar repercusiones económicas que se agudicen a largo plazo (IGBP, 1998; Cox et al., 2000). Además, puede haber una serie de efectos perjudiciales, que pueden ser o no conspicuos, tales como la alteración de las interacciones ecológicas en el océano por la inyección de $\mathrm{CO}_{2}$ (Dalton, 1999) y el aumento de absorción de la radiación solar por la plantación masiva de bosques (Betts, 2000).

La evaluación de la contribución del uso de la tierra y del crecimiento de la vegetación son un punto crítico en el planteamiento de estrategias para mitigar la acumulación de dióxido de carbono en la atmósfera (Caspersen et al. 2000). Por ejemplo, Smaglik (2000) anota que en caso de haber un incremento del crecimiento de la vegetación, el potencial de almacenamiento es cada vez más incierto (ver cuadro 1.). 


\begin{tabular}{|c|c|c|}
\hline \multicolumn{3}{|c|}{$\begin{array}{l}\text { CUADRO 1. INVESTIGACIONES DE INTERPRETACIÓN NEGATIVA, RESPECTO DE } \\
\text { LOS SUMIDEROS }\end{array}$} \\
\hline \multicolumn{2}{|r|}{ Argumentos } & Referencias \\
\hline \multirow{7}{*}{$\begin{array}{l}\text { Factores ambientales que } \\
\text { afectan a los sumideros }\end{array}$} & $\begin{array}{l}\text { - La fertilidad del suelo puede disminuir la res- } \\
\text { puesta de la retención del carbono en la madera, } \\
\text { al aumento de dióxido de carbono atmosférico }\end{array}$ & Oren et al., 2001 \\
\hline & \multicolumn{2}{|c|}{$\begin{array}{l}\text { - La absorción de las emisiones antropogénicas por los ecosistemas } \\
\text { terrestres y oceánicos es sensible a: }\end{array}$} \\
\hline & - Las concentraciones de dióxido de carbono & Schimel et al., 2000. \\
\hline & - El cambio climático & $\begin{array}{l}\text { Cao y Woodward, } \\
\text { 1998; Sarmiento } \text { et al., } \\
\text { 1998; Tian } \text { et al., 1998; } \\
\text { Schimel } \text { et al., 2000. }\end{array}$ \\
\hline & $\begin{array}{l}\text { - El fenómeno del Niño es un control del almace- } \\
\text { namiento terrestre de carbono }\end{array}$ & Keeling et al., 1995 \\
\hline & $\begin{array}{l}\text { - Los incrementos en la temperatura pueden ace- } \\
\text { lerar la descomposición de carbono orgánico con- } \\
\text { tenido en el suelo de los bosques y, en conse- } \\
\text { cuencia, el calentamiento global puede incremen- } \\
\text { tar la liberación de carbono orgánico del suelo a } \\
\text { la atmósfera }\end{array}$ & $\begin{array}{l}\text { Cao y Woodward, } \\
1998\end{array}$ \\
\hline & $\begin{array}{l}\text { - El océano es afectado por el incremento de llu- } \\
\text { via que hace que ocurra estratificación de las } \\
\text { aguas, reduciendo el flujo de carbono hacia las } \\
\text { profundidades y la pérdida de calor a la atmósfe- } \\
\text { ra. El resultado es una disminución en el secues- } \\
\text { tro de dióxido de carbono antropogénico }\end{array}$ & Sarmiento et al., 1998 \\
\hline \multirow{4}{*}{ Ineficiencia } & $\begin{array}{l}\text { - No es evidente la acumulación de carbono en } \\
\text { capas profundas del suelo de los bosques, por lo que } \\
\text { es poco probable la retención de carbono en ellos }\end{array}$ & $\begin{array}{l}\text { Schlesinger y Lichter, } \\
2001\end{array}$ \\
\hline & $\begin{array}{l}\text { - Existe una reducción de } 6 \mathrm{Pg}^{*} \text { de carbono por } \\
\text { año en los sumideros. Almacenar el dióxido de } \\
\text { carbono ha sido estimado en } 200 \text { dólares por } \\
\text { tonelada de emisiones de carbono evitadas. Por lo } \\
\text { tanto, el costo de compensar una pérdida anual de } \\
6 \text { Pg de carbono en los sumideros, sería de } 1,2 \\
\text { billones de dólares anuales }\end{array}$ & Sarmiento, 2000 \\
\hline & $\begin{array}{l}\text { - Si las selvas están creciendo como respuesta a } \\
\text { cambios en el uso de la tierra -nuevo crecimiento } \\
\text { de bosques-, entonces el sumidero se saturará } \\
\text { cuando éstas recuperen su biomasa inicial }\end{array}$ & $\begin{array}{l}\text { Caspersen et al., } \\
\text { 2000; Smaglik, } 2000\end{array}$ \\
\hline & $\begin{array}{l}\text { - La concentración elevada de dióxido de carbono } \\
\text { causa un incremento mayor en la circulación del } \\
\text { carbono que en su almacenamiento }\end{array}$ & Hungate et al., 1997 \\
\hline
\end{tabular}




\begin{tabular}{|c|c|c|}
\hline \multicolumn{3}{|c|}{$\begin{array}{l}\text { CUADRO 1. INVESTIGACIONES DE INTERPRETACIÓN NEGATIVA, RESPECTO DE } \\
\text { LOS SUMIDEROS (CONTINUACIÓN) }\end{array}$} \\
\hline \multirow[t]{2}{*}{ Escalas de tiempo } & $\begin{array}{l}\text { - La adquisición de carbono por parte de los sumideros } \\
\text { puede compensar las emisiones de combustibles fósiles } \\
\text { sólo temporalmente }\end{array}$ & IGBP, 1998 \\
\hline & $\begin{array}{l}\text { - La biosfera actuará como sumidero hasta el 2050, pero } \\
\text { después será una fuente }\end{array}$ & Cox et al., 2000 \\
\hline \multirow[b]{2}{*}{ Efectos perjudiciales } & $\begin{array}{l}\text { - Inyectar dióxido de carbono al océano puede cambiar su } \\
\text { composición química con consecuencias ecológicas perju- } \\
\text { diciales }\end{array}$ & - Dalton, 1999 \\
\hline & $\begin{array}{l}\text { - El secuestro de carbono plantando bosques puede } \\
\text { aumentar el calentamiento en algunas regiones de altas } \\
\text { latitudes. La razón es el oscurecimiento de la superficie } \\
\text { de la tierra por árboles que implica una mayor absorción } \\
\text { de luz solar }\end{array}$ & Betts, 2000 \\
\hline Desconocimiento & $\begin{array}{l}\text { - La tasa a la cual el carbono es acumulado en los ecosis- } \\
\text { temas terrestres y los mecanismos responsables del fun- } \\
\text { cionamiento de los sumideros son inciertos }\end{array}$ & $\begin{array}{l}\text { Sundquist, 1993; } \\
\text { Houghton et al., } \\
\text { 1999; Smaglik, } 2000\end{array}$ \\
\hline
\end{tabular}

Fuente: ROSAS, C.A. y elaboración propia

El inconveniente de confiar en los sumideros como solución a la mitigación de los efectos del cambio climático se debe en parte a su fragilidad. Las actividades antropogénicas pueden hacer desaparecer rápidamente estos reservorios, como ocurre en los casos de la deforestación (Chambers et al., 2001) o del uso del fuego (Smaglik, 2000). La quema de bosques presenta, entre otros, el problema de que no es debidamente controlada por autoridades competentes. Sin embargo, el incremento de la masa de árboles seguido de la supresión del fuego causa el almacenamiento de carbono en los bosques (Tilman et al. 2000).

La conservación de los bosques, desafortunadamente, no está incluida en el Mecanismo de Desarrollo Limpio (Clean Development Mechanism) del Protocolo de Kyoto (Bonnie et al. 2000). No obstante, es evidente que su conservación genera beneficios significativos local y globalmente, por ejemplo en lo que respecta al uso del recurso maderable y la agricultura (Kremen et al. 2000). El problema radica en que, a nivel nacional, los beneficios financieros de estos dos tipos de actividades son más grandes que los de la conservación. Por esta razón, Kremen y colaboradores (2000) sugieren que el Protocolo de Kyoto podría superar este obstáculo creando mercados para la protección de bosques tropicales para mitigar el cambio climático. Estos mercados tendrían que ser eficientes puesto que aún permanecen los elevados costes de compensación por pérdidas anuales en los sumideros (Sarmiento, 2000).

La retención terrestre de carbono sólo es una solución parcial en el control del aumento de las emisiones de $\mathrm{CO}_{2}$ a la atmósfera (Chambers et al., 2001). No tiene sentido basar todo el esfuerzo para mitigar los efectos del cambio climático en la utilización de sumideros. Tampoco el argumentar, aunque sea cierto, que los terrenos utilizados para cultivos y pastoreo son sumideros, solamente para desentenderse del 
problema del paradero de las emisiones al asegurar que estas superficies de tierra contrarrestan los efectos producidos por las actividades industriales de uno u otro país (Smaglik, 2000). Por otra parte, aunque se diga que todos los ecosistemas manejados y no manejados deberían ser considerados sumideros terrestres (para evitar la sorpresa de grandes liberaciones no anticipadas de carbono, IGBP, 1998), todos los países deberían centrar sus esfuerzos en adoptar medidas determinantes para reducir las emisiones de carbono a la atmósfera. Se deberían adoptar este tipo de medidas, en lugar de que los países industrializados apoyen proyectos de reducción de emisiones de gases de efecto invernadero en países subdesarrollados y no en los propios (Smaglik, 2000). Es por esto por lo que, estas consideraciones permiten concluir que los sumideros no son una panacea y que existen medidas por tomar que no han entrado en vigor debido a intereses diversos, como la reducción de las emisiones.

\section{ALGUNOS ASPECTOS BIOLÓGICAS DEL CAMBIO CLIMÁTICO}

La multiplicidad de relaciones establecidas entre los factores antrópicos y naturales, así como su influencia sobre los procesos ecológicos clave asociados a uno o más niveles de organización, atribuye al estudio del CC una dificultad ineludible. Los cambios observados en los sistemas biológicos son la respuesta resultante a lo que se ha denominado "Cambio Global". Los efectos del cambio en los usos del suelo, la fragmentación de hábitats, el incremento en la deposición de nitrógeno, la introducción de especies alóctonas y sus interacciones sobre el medio son difíciles de cuantificar aisladamente de los efectos generados exclusivamente por el hipotético cambio climático.

Si nos detenemos en las presiones que el cambio climático puede generar en los ecosistemas (terrestres, acuáticos,...), nos encontramos con que éste supone una importante presión adicional sobre los ecosistemas terrestres, afectados ya seriamente en la actualidad por la contaminación, la sobreexplotación y la fragmentación del territorio. El Panel Intergubernamental de Cambio Climático (IPCC, 2007) indica, en base a modelos predictivos, que en promedio el 33\% del área forestal actual se verá afectada a causa de cambios en la frecuencia e intensidad de los fuegos, la distribución del agua y la diversidad de la vida silvestre (Dale, 2001). Scott et al. (2000) y Mouillot et al. (2002), entre otros, han estudiado los efectos del cambio climático en relación a la frecuencia e intensidad de los fuegos en la vegetación subártica y mediterránea respectivamente, constatando que el calentamiento adelanta los fuegos y los hace más largos, dejando como resultado fases de sucesión temprana (estepa-pastizal) que dominan el paisaje.

Los efectos sobre los ecosistemas terrestres varían de unas regiones a otras. Así, los bosques subtropicales secos en Zimbabwe podrían disminuir cerca de un $45 \%$. En México se espera que los bosques secos se expandan, mientras la cobertura de los bosques tropicales montanos húmedos probablemente se vea reducida. En las regiones tropicales también se prevén cambios en la estructura y composición de sus masas forestales, debido a su sensibilidad a las variaciones en la disponibilidad de agua y humedad del suelo. En los bosques boreales y templados el aumento de tem- 
peratura podría ampliar los rangos temporales de crecimiento y reproducción, favoreciendo su expansión hacia los polos, pero incrementando a su vez la frecuencia de fuegos y brotes de plagas.

Un incremento de un grado centígrado puede causar cambios significativos en la composición y distribución de ciertas poblaciones vegetales y, de acuerdo con el IPCC (2009) se espera un reemplazamiento de los árboles que asociamos a bosques maduros (especies de lento crecimiento) por árboles y arbustos de rápido crecimiento asociados con áreas perturbadas. Asimismo, se prevé que la distribución de la vegetación se desplace a mayor altitud a un ritmo de 8-10 m por década por lo que algunas especies limitadas a las cumbres montañosas podrían extinguirse. Otros estudios muestran que los márgenes de distribución de algunas especies de aves y mariposas también se han desplazado más al Norte y a mayor altitud (por ejemplo, 18,9 $\mathrm{km}$ en promedio para aves británicas según Thomas y Lennon, 1999 y $2^{\circ}$ en latitud para la mariposa Euphydryas editha según Parmesan, 1996). Con el propósito de determinar la certeza de este tipo de predicciones, Samways et al. (1999) trabajaron con mariquitas (Coccinellidae: Chilocorus spp.), con la conclusión que sólo para el $26,7 \%$ de las especies analizadas se podían predecir cambios con el $100 \%$ de certeza, lo que alerta de un cierto error asociado a este tipo de estudios.

Por otra parte, señalar que las masas de agua continentales constituyen uno de los ambientes más vulnerables a los efectos generados por el cambio climático. Al mismo tiempo, diversos organismos internacionales resaltan su importancia como principales amortiguadores de estos efectos.

A nivel mundial las afecciones pueden ser muy graves. En EEUU se estima que una subida de tan sólo un pie (0,3048 metros) en el nivel del mar eliminaría del 17 al $43 \%$ de sus humedales (EPA, 2002). Las zonas áridas y semiáridas parecen ser las más vulnerables a la disminución de las precipitaciones, como ha experimentado el gran Lago Chad con la dramática disminución de su superficie desde los años sesenta del pasado siglo. Los humedales situados en latitudes elevadas son especialmente vulnerables al calentamiento global y se prevé un cambio en su distribución hacia el Norte. En la Península Ibérica, los veranos serán más secos y pondrán en peligro hábitats como los de Doñana.

Los sistemas costeros se verán afectados debido al aumento del nivel del mar y de la temperatura del agua, así como al mayor riesgo de tempestades. Así, las costas bajas de Affrica occidental y central están expuestas a riesgos de erosión e inundación y una fracción del delta del Nilo podría perderse; en Europa algunas áreas costeras se hallan ya bajo el nivel medio del mar y muchas otras son vulnerables a mareas de tempestad; y en las costas bajas y estuarios de América Latina, el aumento del nivel del mar podría reducir la línea de costa y gran parte de su diversidad biológica. En el Ártico se espera una pérdida considerable de hielo, lo cual aumentaría las inundaciones en otros puntos geográficos y transformaría el paisaje en gran medida. En la Antártica los cambios que se esperan son menores, pero podrían motivar el desplazamiento de algunas especies hacia el polo y muchas otras, dependientes del hielo, podrían encontrarse en desventaja en ambas áreas polares. 
Las alteraciones en pocos grados de la temperatura del mar pueden acarrear también importantes alteraciones tróficas. En las islas Galápagos, durante el fenómeno del Niño de 1997-1998, la superficie del agua aumentó su temperatura y gran número de organismos filtradores murieron a consecuencia de la disminución del plancton del que se alimentaban, alterando la red trófica.

\section{CAMBIO CLIMÁTICO, RIESGOS NATURALES Y TECNOLÓGICOS EN ESPAÑA}

Junto con la realidad expuesta, la del clima y el denominado cambio climático, a la hora de reflexionar sobre los denominados "Riesgos Naturales y Tecnológicos" que afectan o pueden incidir en nuestro país, a pesar de todos los pesares, como con respecto al cambio climático, debemos de ser optimistas. No podemos permitirnos el lujo de afirmar con Chesterton (Manalive) "sí, somos tan vulgares y violentos, hemos hecho tantas cosas malas, que resulta vergonzoso que tengamos razón". Hoy el acceso a la información ambiental es ya un derecho, y como tal debemos transmitírselo a nuestros alumnos y alumnas, aplicando tanto la "Ley sobre derecho de acceso a la información en materia de medio ambiente" como el "Convenio de Aarhus". Si tomamos como punto de partida una publicación reciente del Ministerio de Medio Ambiente (AA. VV. (2009). Perfil ambiental de España. Informe basado en Indicadores), observaremos que los temporales marítimos y las inundaciones son la causa principal de la pérdida de vidas humanas por riesgos naturales

Como consecuencia del conjunto de fenómenos naturales, en España se han producido 704 fallecimientos en el período 1995-2008, lo que equivale a una ratio de 0,0172 muertos por mil habitantes. En concreto, en el período considerado las inundaciones han provocado más del $31 \%$ de las víctimas, los temporales marítimos más del $25 \%$ y las tormentas (rayos y vientos fuertes) cerca del $20 \%$. Un caso especial en el conjunto de los riesgos naturales es el que presentan las avenidas y las inundaciones, especialmente en el área mediterránea. Las características meteorológicas en estas zonas dan lugar a que se produzcan en pocas horas precipitaciones que alcanzan valores superiores al promedio anual. Estas lluvias extraordinarias provocan caudales extremos habitualmente denominados crecidas, avenidas o riadas que al desbordar los cauces habituales provocan la inundación de los terrenos adyacentes. En muchas ocasiones éstos han sido invadidos antes por edificaciones e instalaciones, con el consiguiente aumento de riesgos.

En nuestro país, las zonas de mayor desproporción entre los caudales ordinarios y los extraordinarios, y, por tanto, zonas de riesgo con alta probabilidad de sufrir avenidas, son la cuenca del Ebro, una franja variable del litoral Mediterráneo (incluidas las islas Baleares), zonas localizadas de las islas Canarias y otros puntos dispersos por la Península.

En la mayoría de los casos las consecuencias de las avenidas se valoran por los daños materiales que provocan, aunque no siempre es así. El caso más dramático de los últimos años fue la catástrofe de Biescas (Barranco de Arás, Huesca, en agosto de 1996) en la que se produjeron 87 víctimas mortales. Otro ejemplo destacable se 
produjo en marzo de 2002, cuando una gran tromba de agua sobre Santa Cruz de Tenerife originó 8 muertos, 30 heridos y daños materiales que superaron los 100 millones de euros. En el período 1990-2008, el número total de víctimas mortales por avenidas e inundaciones en España ha sido de 323, destacando el elevado número de Aragón (por la ya mencionada catástrofe de Biescas), Andalucía, Cataluña y Extremadura, todas ellas con más de veinte víctimas mortales.

El cambio climático es una verdadera realidad siempre que lo entendamos como la crisis por la que está pasando el clima de nuestro planeta, especialmente acusada a partir de mediados del pasado siglo, y que en los últimos años -lejos de remitir- se está mostrando cada vez de forma más nítida. Al hacerse eco los "mass media", suele mostrarse a la población en general, el susodicho cambio climático como una amenaza para el futuro de la Humanidad, de la cual el principal responsable es el hombre, y que por consiguiente, está en sus manos evitarla. Nada más alejado de la realidad, el hombre no tiene poder para evitar el recalentamiento de la atmósfera, y mucho menos para estabilizar el clima. El incremento de la concentración en la atmósfera de gases manta originados por dichas emisiones, es consecuencia de la atención a necesidades vitales inherentes al desarrollo y expansión de la propia especie humana (de aquí que, intentar imponer medidas restrictivas que frenen el cambio climático es más un elemento propio de mercado, que una realidad física, por ello es como poner puertas al campo).

Las primeras referencias a este fenómeno las tenemos en el año 1827. El matemático francés Jean Baptiste Fourier observa, por primera vez, que ciertos gases, en particular el dióxido de carbono, retienen el calor atmosférico. En su parecer este fenómeno es similar al que ha visto en los invernaderos y por ello crea el termino "effet de serre". Desde entonces el "efecto invernadero" ha sido el nombre genérico dado a esta temática.

Las investigaciones científicas prosiguen y en 1860 el físico irlandés J. Tyndall, destacado por sus investigaciones sobre la difusión de la luz a través de las suspensiones coloidales y de sus estudios sobre el deshielo, profundiza en el estudio del clima y deduce que las concentraciones de $\mathrm{CO}_{2}$ en la atmósfera y sus variaciones, afectan a los cambios climáticos. Sus estudios marcan una pauta de investigación que otros científicos, en años posteriores, profun-dizarán llegando a conocimientos más concretos y detallados. En 1903 el Premio Nobel de Química fue otorgado al físico sueco Svante Arrhenius. "como reconocimiento a sus grandes méritos adquiridos gracias a la formulación de sus teorías acerca de la disociación electrolítica y en el desarrollo de la química". El autor de la teoría de los iones que permite interpretar las leyes de la electrólisis y explica las propiedades químicas de las soluciones de electrólitos, no se limitó a estas disciplinas sino que también realizó investigaciones sobre el clima, llegando a deducir que duplicando la concentración de $\mathrm{CO}_{2}$ en la atmósfera, la temperatura aumentaría 5 ó $6^{\circ} \mathrm{C}$. Estas conclusiones han sido validadas posteriormente y forman parte de los conocimientos aplicados en la extrapolación de la actual situación climática que estiman un calentamiento progresivo de la superficie terrestre. En cualquier caso, aunque las emisiones de gases invernadero sigan aumentando de manera incontrolada, el calentamiento tendrá un límite, que una vez 
sea alcanzado -de no intervenir otros factores ajenos al propio efecto invernadero- la temperatura media global se mantendrá constante, independientemente de cualquier incremento posterior de las concentraciones de dichos gases

Por ello, a pesar de todas las predicciones más o menos catastróficas, nos parece cuando menos sorprendente que un aumento tan poco importante de la temperatura pueda suponer un cambio climático capaz de transformar la faz de la Tierra (dado que el calentamiento producido por el efecto invernadero se debe a la absorción por la atmósfera de la radiación calorífica emitida por la superficie terrestre, el calentamiento cesará cuando no exista más radiación por absorber; de hecho, casi el $95 \%$ de la radiación terrestre es ya absorbida, escapando el resto directamente hacia el espacio exterior a través de la denominada "ventana atmosférica", señalándose un límite de calentamiento no superior a los dos grados y medio). Así pues, hay notables incertidumbres, mas la información es suficiente para tomar medidas de forma inmediata.

\subsection{CAMBIOS EN LOS COTEXTOS DEL DESARROLLO}

De los geógrafos se espera que den respuestas de geógrafos. Nada más normal a la hora de tratar sobre el período que estamos viviendo en los momentos actuales los prolegómenos del siglo XXI-; podríamos afirmar sin temor a equivocarnos, que uno de los aspectos que le caracterizan es el de un creciente y, en ocasiones, desmesurado y no siempre controlado desarrollo tecnológico, de cuyos efectos hemos empezado a tomar conciencia. Una de las causas ha sido la consideración de las anomalías y variantes que, como consecuencia del referido fenómeno, se están produciendo en nuestro entorno; todo ello resumido en la creciente preocupación por el medio ambiente, en el contexto de la Geografía Regional.

Lejos de ser este un problema circunscrito a un determinado ámbito, el que nos preocupa es prácticamente multisectorial e interdisciplinario, por lo que es difícil que alguien se sienta ajeno o desvinculado del mismo (y menos como geógrafos que somos). Por contra, todo parece indicar que la necesidad de cuidado y mejora de nuestro entorno es un derecho y un deber que todos, individual y colectivamente, debemos asumir como un reto, sobre todo pensando en las generaciones futuras.

El hombre siempre ha tendido a forzar a la naturaleza, a derivar en beneficio propio los flujos de energía que coadyuvan al funcionamiento de los ecosistemas. No contento con satisfacer sus propias necesidades energéticas metabólicas, ha tendido siempre a aumentar el consumo de energía externa -no metabólica con la que transformar y organizar el mundo a su conveniencia inmediata. De hecho, a más energía externa disponible, más poder, y -por ende- mayor capacidad competitiva. Esta no es una característica del pensamiento científico, sino del comportamiento humano. Si el hombre es más capaz que otras especies de actuar intensamente sobre el medio, esto debiera atribuirse a su poder de raciocinio - del que la ciencia es una consecuencia-, y no a la ciencia en sí misma. La crítica genérica a la ciencia y a la técnica es, en el fondo, una crítica a la capacidad de pensar, y como tal sería muy discutible (Tarrades, 1990). 
De un lado, cabe argumentar que nos encontramos ante una apuesta de alcance bipolar por parte de una nebulosa denominada "terrorismo internacional" que parece perseguir dos, en primer lugar, la globalización de su empeño, en el sentido de que nadie ni nada sea invulnerable; en segundo lugar, consolidarse como único poder alternativo -aunque sólo lo sea para la destrucción.

En la actualidad la aldea global ha sido sustituida por el mercado global, dando lugar al tratado tema de la globalización, que, en su actual modalidad neoliberal, tiene carácter excluyente tanto de continentes enteros, los más subdesarrollados, como de sectores cada vez más amplios de los países desarrollados, los que no se adaptan a la permanente renovación tecnológica. Así, podemos plantearnos el siguiente interrogante: ¿por qué los modelos de desarrollo regional? "Es incontestable", afirma Enzensberger, "que el mercado mundial, desde que dejó de ser una visión lejana y se convirtió en realidad global, fabrica cada vez menos ganadores y más perdedores, y eso no en el Tercer Mundo o en el Segundo, sino en los altos centros del capitalismo. Allá son países y continentes enteros los que se ven abandonados y excluidos de los intercambios; aquí son sectores cada vez más grandes de la población los que, en la competencia cada día más grande por las calificaciones, no pueden seguir y caen".

Desde esta perspectiva, los modelos de desarrollo regional pueden servir al doble reto de aproximar al desarrollo los países subdesarrollados, y encontrar un equilibrio entre globalización y regionalización. En este sentido, deben convertirse en un coadyuvante más, al servicio de los Estados, regiones,..., para superar las diferencias SurNorte, colocar la economía al servicio del desarrollo integral de las personas y los pueblos, denunciar el carácter idolátrico del capital, defender la democratización de los Estados en torno a los valores comunitarios,... (Tamayo-Acosta, J.J. 1999). ¿Qué repercusiones territoriales tendrán tal o cual acontecimiento? Las respuestas son multidimensionales, en una ciencia -la Geografía- poliparadigmática. Tras los acontecimientos de septiembre último, la globalización vuelve a mostrarnos la idea según la cual es un negocio de Gobierno, más que un gobierno de los negocios. Las divisiones que separan al mundo , tanto entre países pobres y países ricos, como dentro de estos últimos, parecen aún menos aceptables. Se comprende mejor que la globalización también es un discurso retórico de legitimación de las ganancias de los vencedores - tanto entre naciones como en el seno de las mismas- y que con frecuencia sirve los intereses de un corporativismo de ricos (más que el mérito comparado de cada uno, es la estructura del mundo -descendiendo hasta el específico de la Universidad- la que permite a unos ganar y a otros perder).

Dar respuesta a interrogantes como los anteriores, nos obliga a plantearnos la base conceptual del "subdesarrollo", o por alusión su antónimo "desarrollo". La revisión de la ya abundante literatura especializada conduce a un sinnúmero de definiciones que más que enmarcar el fenómeno lo que hacen es caracterizar o tipificar alguna o algunas de sus manifestaciones, las más de las veces con criterios productivistas ajenos, en general, a la inseparable dimensión social que acompaña a las variables económicas. Los países occidentales han utilizado con frecuencia su supremacía y el poder de persuasión que da el dinero, o que emana de las propias estruc- 
turas, para explotar a los países pobres o para mantener en el poder, en ellos, a regímenes corruptos.

Como señalan distintos estudiosos, es obvio que todos intuimos lo que es el subdesarrollo, pero nadie -acabamos de apuntarlo- lo ha definido con precisión. Está claro que no es sólo una situación económica deprimida, y mucho menos un estadio cultural atrasado, pues dentro de la extensa gama de países incluidos en esta categoría, los hay con culturas milenarias riquísimas, y tampoco parece que todos los países desarrollados puedan darles lecciones en este terreno.

Es indudable, en cambio, que la condición de país subdesarrollado lleva consigo una situación de dependencia -política, económica, técnica,...- de otra potencia o de un grupo económico extranjero; supone también, en muchas ocasiones, una falta de participación política de su población en las tareas de gobierno, unas veces porque carece de preparación suficiente y otras porque se le impone una forma de administración sea paternalista o tiránica, que la excluye de ella. El subdesarrollo lleva implícito, desde luego, un nivel de vida extremadamente bajo, un predominio de población rural, un alto grado de analfabetismo, de paro total y paro encubierto; hambre y malnutrición crónicas, por tanto, a veces en grado muy difícil de imaginar, que hacen casi imposible el trabajo intenso y continuado: alta mortalidad infantil, morbilidad muy acusada, mala situación de la mujer - discriminada y considerada inferior- $\mathrm{y}$, en ciertos países -como es de sobra conocido-, una administración incompetente, arbitraria, venal y corrompida.

Las nociones de desarrollo y subdesarrollo corresponden a la óptica occidental, materialista -trátese de capitalismo y comunismo-, que da prioridad a los temas de carácter económico. Desde este punto de vista la diferencia entre unos y otros países es palmaria e innegable. Pero, desde el lado de los países subdesarrollados, ¿podemos decir que comparten los puntos de vista de la población de los países industriales? Indudablemente, no se puede contestar de un modo simplista, pero puede creerse que una buena parte de sus habitantes miran las cosas y la vida con ojos muy distintos. Insistimos una y mil veces en que no es sólo lo económico lo que caracteriza el subdesarrollo de los pueblos y las regiones, aunque quizá, a pesar de sus enormes dificultades, lo económico es lo más fácil de detectar y medir.

El tema del subdesarrollo es, ante todo y esencialmente, profundamente humano: tres cuartas partes de la humanidad padecen sus consecuencias, y eso se refleja en todos sus aspectos demográficos. Por todos los lados del análisis de las características de la población mundial -tasas de natalidad y mortalidad, índices de crecimiento, estructura por edades, composición profesional de la población, esperanza de vida, condiciones de la mujer, grado de instrucción, renta per cápita,...- encontraremos - con todas las gradaciones y matices que dan las diferencias entre las poblaciones de los países ricos y las poblaciones de los países pobres, entre los países desarrollados y los subdesarrollados. Es lógico -lo contrario sería imperdonable- que el interés humano del tema -es la vida de millones de otros hombres lo que está en juego- atraiga no sólo la atención de los científicos, resultando muy doloroso comprobar -aunque nadie que conozca un poco la historia puede sorprenderse-cómo las grandes potencias emplean a estos países como peones, y cabezas de puente, en el 
trágico juego de la estrategia universal, condicionando su ayuda a que se muevan según su conveniencia.

Desde la perspectiva del desarrollo regional, los intereses se plasman en unos modelos que reflejan la historia del siglo XX, y más concretamente tras la Segunda Guerra Mundial, lo que se conoce como el círculo fordista basado en la producción de masas y de consumo de masas. Más aún, se podría plantear que la fase de acumulación del capital en esa época se enmarca forzosamente en una forma concreta que toma el Estado -el Estado de Bienestar-, el sindicalismo reivindicativo y el crédito al consumo. Estos factores permitieron así la relación entre producción y consumo, que fueron esenciales en la explicación del modelo de desarrollo de los años de oro.

No obstante, a partir de los años setenta los distintos análisis han señalado los cambios profundos en los resultados del modelo de crecimiento : el avance del desempleo, la precariedad y la exclusión se convertirían en los aspectos más importantes y no sólo en los países no industrializados, sino de los industrializados. Como señalan distintos informes, éstos tuvieron altas tasas de crecimiento económico entre los años 1973 y 1987, pero también se conocieron las mayores tasas de desempleo. El motivo es que la mayor parte de la producción de los países industrializados procedió de incrementos de la productividad total y el resto de un aumento de inversiones de capital, sin que se crearan nuevos puestos de trabajo.

La crisis de la acumulación en esta fase ha llevado así a una cierta reestructuración financiera en las actividades económicas en general y un reajuste en la relación empresarios/asalariados.

Es un hecho el que quizá deberíamos recurrir a una síntesis actualizadora, seleccionando de cada teoría tratada lo que aún pensemos que sigue siendo válido o útil. Somos, no obstante, conscientes al llegar a este punto que son muchos los interrogantes que quedan sin una contestación. ¿Por qué ninguna teoría ha sido capaz de darnos las soluciones que coadyuvaran a la erradicación del subdesarrollo? ¿Las interpretaciones que se han realizado, no son correctas? ¿Cuál es el papel a desempeñar por éstos?

La aproximación al tema tratado pasa por la puesta en práctica de destintos modelos de desarrollo regional que, desde la diversidad ideológica, permita superar el "monolitismo" del modelo en la actualidad vigente, y cuyas características estamos estudiando, marcándonos "a priori" la necesidad y utilidad de los susodichos modelos.

Lo que se está poniendo sobre el tapete no es un debate económico sobre el tema del desarrollo, sino uno de carácter político en el que sobresalen dos cuestiones: si nos consideramos tan satisfechos con lo conseguido en la búsqueda de la superación de la desigualdad, como para eliminarla de las prioridades públicas, al menos, en cuanto a la intensidad de los recursos dedicados, y, en segundo lugar, qué ha cambiado en nuestra sociedad para que se esté dando esa resistencia por parte de los ricos a la solidaridad pública. Descartando, por tanto, un regreso al enfrentamiento, al odio, como estrategia, es evidente que deben buscarse modelos de desarrollo que coadyuven a la superación de los problemas descritos; este análisis conduce a reconocer la necesidad de una política de desarrollo regional, pues un desarrollo limitado a ciertas regiones pre- 
senta un doble inconveniente: por una parte, deja sin emplear o deficientemente utilizados los recursos materiales y humanos de las regiones pobres; por otra, suscita en las regiones más ricas y desarrolladas una ley de rendimientos decrecientes.

Como hemos expuesto con anterioridad a la hora de tratar de los modelos de desarrollo nos lleva hasta los elementos que sirven de base para confeccionar una teoría de desarrollo, entendiendo las teorías como hipótesis que nos permitan entender los orígenes, procesos y consolidación de las disparidades regionales, para que "a posteriori" puedan aplicarse los modelos que favorezcan el referido desarrollo regional. Los orígenes como señala Lázaro, J (1977) probablemente debamos buscarlo en el papel que las teorías clásicas han asignado al comercio internacional como difusor del desarrollo, basándose en el supuesto de la movilidad de los factores productivos y de bienes y servicios, llegándose a la conclusión de la tendencia casi determinista a un nivel de desarrollo similar en todos los países; sin embargo, la realidad ha desmentido tan optimistas e irreales previsiones.

Sin duda, de la superposición de éstos y de otros enfoques no mencionados, surgen interpretaciones que intentan comprender y explicar por qué unas regiones se desarrollan y otras no. Pese a todo de lo que no nos cabe duda en la actualidad es que el equilibrio territorial y regional alcanza particular importancia, sobre todo cuando se comprueba que en no pocas regiones subdesarrolladas la distribución de la riqueza y de la renta es más injusta que en las desarrolladas. Es por esto por lo que, si la opción por eliminar los desequilibrios tiene sentido es como instrumento para potenciar una redistribución de la renta entre las personas, junto con unos mejores y más justos niveles de bienestar y calidad de vida. Los modelos de organización y desarrollo regional se convierten de esta manera en un instrumento más para facilitar la consecución de los objetivos últimos de una transformación más justa de la sociedad. Pese a todo, debemos de ser conscientes de que la transformación de una determinada organización del espacio regional mediante la aplicación de estos modelos, se encuentra con no pocas resistencias al cambio, convirtiéndose en un objetivo a alcanzar a medio o largo plazo (quizá como alternativa para quienes echaban en falta una nueva geopolítica, tras el fin de la bipolaridad y su tranquilizadora geometría a dos, éste puede ser el esbozo de una futuras líneas de fuerza planetarias; el mundo se mueve hoy, agitado, en busca de un nuevo mapa geopolítico de sí mismo).

Pocos autores han sabido reflexionar sobre este tema como Sergio Boisier; sin embargo, vamos a seguir los análisis del profesor Elies Furió (1994), para quien la idea del desarrollo local es presentada fundamentalmente bajo dos acepciones. Ambas recogen algunos de los elementos esenciales propios de la nueva dinámica económica contemporánea, pero también muestran ciertos sesgos. En un primer momento, el desarrollo local significaría, esencialmente, el desarrollo partiendo de la base frente al desarrollo desde la "cúpula", el deseo de cortar las lógicas dominantes que conducen a una desestructuración de los territorios y de las solidaridades locales.

En un segundo momento, el desarrollo local se inclinaría hacia una apología de la salida de la crisis mediante la pequeña y mediana empresa. Esta concepción comparte con la anterior el ideal del desarrollo desde la base, pero éste es interpretado en su "primer grado": al mostrarse la creación de nuevas pequeñas empresas en la base, 
éste proceso se denominará "desde abajo". Tanto en un caso como en el otro, estas ópticas pueden conducir a callejones sin salida de no percibir correctamente la profundidad de las mutaciones de la técnica y la organización de la producción, de la división espacial del trabajo y de la propia actuación pública (Greffe, 1988)

Desde este punto de vista, el desarrollo local es interpretado como el resultado del deseo de vivir, trabajar y decidir el destino de la propia comunidad territorial, la necesidad por parte de cierto número de agentes sociales y de poderes públicos locales de responder al desafío del desempleo y la confianza en las pequeñas dimensiones empresariales. Estas preocupaciones adquieren sentido si se recuerdan algunas de las manifestaciones de las últimas crisis económicas; la desaparición de la confianza de la contribución exitosa de las grandes empresas respecto a las posibilidades de desarrollo local, la evidencia de la dependencia frente a las decisiones tomadas en centros lejanos, la pérdida o desaparición de las producciones locales,... Por tanto, al desarrollo realizado desde arriba se opone el realizado desde la base; a las lógicas aterritoriales de la economía capitalista se opone el interés local; a una lógica del beneficio que parece ser destructora se contrapone el deseo de satisfacer las necesidades de los consumidores y de los trabajadores, aunque esto implique el recurso a formas de producción diferentes o alternativas.

Los partidarios de este esquema han admitido siempre que implicaba riesgos. En territorios desigualmente provistos de recursos, estrategias de desarrollo desde la base podían conducir a estimular disparidades naturales o creadas artificialmente; y es que, el desarrollo local no ha conseguido nunca librarse de las acusaciones de autarquía. Al admitir de entrada la posibilidad de que se solucionasen localmente las necesidades a través de la producción, el desarrollo local dejaba creer que se podía vivir al margen o, incluso, fuera de la división internacional del trabajo con todo lo positivo que ésta implica; también se olvidaban las consecuencias negativas que sobre la economía local puede tener una mala inserción en la división interespacial del trabajo.

No debemos olvidarnos de que a este sesgo autárquico corresponde un medio rural; la cuestión de una cierta protección frente a los problemas de la división internacional del trabajo y de un cierre local de la economía corresponde mejor, de entrada, a medios rurales que a medios urbanos, en los que resulta difícil protegerse de la división internacional del trabajo. Este planteamiento en favor de lo "rural" y en detrimento de lo "urbano", no ha contribuido a reforzar el carácter innovador del desarrollo local. Y, también, a subestimar la problemática que puede encerrar una base productiva agraria deficiente (Greffe, 1988)

Un último problema es la falta de un mínimo de articulación entre el ámbito local y el ámbito estatal. En muchas ocasiones se ha pensa que era posible el desarrollo local al margen de las regulaciones definidas a nivel nacional. Es cierto que algunas de las modalidades de regulación estatales se muestran ineficaces para resolver ciertos problemas; aunque no está claro que esto se resuelva mediante la regulación regional y local. Pese a todo, sería erróneo concluir de lo anterior la escasa oportunidad del concepto del desarrollo local y de una estrategia fundamentada en el mismo, como un elemento básico para un mejor entendimiento de los modelos de desarrollo regional; pues, esta estrategia del desarrollo local ha demostrado, más que 
nunca, que la movilización de las fuerzas y su coordinación mediante proyectos colectivos es una condición "sine qua non" del desarrollo en un período de reestructuración. Iniciar una concertación, clarificar los proyectos de unos mediante los otros, y reforzar así sus posibilidades de realización, esto significa también obligarse a elegir interlocutores, definir terrenos de concertación y correr el riesgo de sacar a la luz intereses que no tienen por qué converger.

Aunque sea ésta la aportación más destacada, también se puede deducir de ella otra consecuencia: "a pesar de que no sea un modelo, el desarrollo local es, como mínimo, un método para aproximarse a los problemas" (Greffe, 1988); o, como expresan otros autores, esta perspectiva es ante todo una aproximación territorial al desarrollo. Parafraseando al profesor Vázquez Barquero (1998), la conceptualización de desarrollo local se puede relacionar con la confluencia de dos líneas de investigación: una, más bien de carácter teórico, que nace como consecuencia del intento de encontrar una noción de desarrollo, que permita la acción pública para el desarrollo de localidades y regiones; otra, de carácter histórico, que surge como consecuencia de la interpretación de los procesos de desarrollo industrial en localidades y regiones del sur de Europa. La capacidad de liderar el propio proceso de desarrollo, unido a la movilización de los recursos disponibles en el área, de su potencial de desarrollo endógeno, conduce a una forma de desarrollo que ha venido en denominarse desarrollo endógeno o desarrollo local. Este concepto de desarrollo reúne un conjunto de rasgos y características, que le dan una configuración específica. Ante todo, hay que decir que el desarrollo local hace referencia a procesos de acumulación de capital en localidades y territorios concretos. La disponibilidad de una oferta de mano de obra, suficientemente cualificada para las tareas que realiza, y poco conflictiva, unido a una capacidad empresarial y organizativa, fuertemente articulado a la tradición productiva local y a una cultura atenta a las innovaciones al cambio y favorece la acumulación de capital en los sistemas productivos locales.

Se trata de procesos de desarrollo difuso, que se caracterizan por la organización sistémica de las unidades de producción, que permite a las empresas locales competir en los mercados nacionales e internacionales. Los procesos de desarrollo endógeno se producen gracias a la utilización eficiente del potencial económico local que permiten las instituciones y mecanismos de regulación que caracterizan a cada territorio. La forma de organización productiva, las estructuras familiares y tradiciones locales, el tejido social y cultural y los códigos de conducta de la población condicionan los procesos de desarrollo local, favorecen o limitan la dinámica económica $y$, en definitiva, determinan la "senda" específica del desarrollo de las economías locales y regionales.

Además, el desarrollo local endógeno obedece a una visión territorial (y no funcional) de los procesos de crecimiento y cambio estructural, que parte de la hipótesis de que el espacio no es un mero soporte físico de los objetos, actividades y procesos económicos, sino que es un agente de transformación social. Cada territorio se vincula al sistema de relaciones económicas de un país en función de su especificidad territorial, de la identidad económica, política, social y cultural. 
El concepto de desarrollo local endógeno concede un papel predominante a las empresas, a las organizaciones, a las instituciones locales, y a la propia sociedad civil, en los procesos de crecimiento y cambio estructural. Es una aproximación «de abajo-arriba» al desarrollo económico, que considera que los actores locales, públicos y privados, son los responsables de las acciones de inversión y del control de los procesos. Puede decirse que el desarrollo local endógeno es un proceso de crecimiento económico y cambio estructural, que conduce a una mejora del nivel de vida de la población de la localidad, en el que se pueden identificar al menos, tres dimensiones: una económica, caracterizada por un sistema específico de producción que permite a los empresarios locales usar, eficientemente, los factores productivos y alcanzar niveles de productividad suficientes para ser competitivos en los mercados; otra sociocultural, en que el sistema de relaciones económicas y sociales, las instituciones locales y los valores sirven de base al proceso de desarrollo; y otra política y administrativa, en que las iniciativas locales permiten crear un entorno local favorable a la producción e impulsar el desarrollo sostenible.

Desde esta perspectiva, frente al modelo de crecimiento concentrado y desarrollo desde arriba, tal y como hemos expuesto, ha ido definiéndose en los últimos años el paradigma de desarrollo autoconcentrado y difuso, basado en la utilización productiva de los recursos locales. Al menos en teoría, las comunidades territoriales disponen de un conjunto de recursos (económicos, humanos, institucionales y culturales), que constituyen las potencialidades de desarrollo endógeno de un área. En el entorno local se detecta, por ejemplo, la dotación de una determinada estructura productiva, mercado de trabajo, capacidad empresarial, recursos naturales, estructura social y política, o tradición y cultura, sobre la que puede articularse su crecimiento económico y la mejora del nivel de vida de la población.

Es importante subrayar que la atención prestada a los modelos locales de desarrollo no es sólo el resultado de la diferenciación de situaciones económicas locales y la emergencia de nuevas formas de industrialización y desarrollo, sino, también, es una consecuencia de la crisis del "paradigma funcionalista" de desarrollo, que consideraba al espacio como un simple lugar donde ocurrían los efectos de los procesos de desarrollo general.

Los actores ocupan un lugar central, empero este reconocimiento es insuficiente para entender el desarrollo local. El análisis no debe ser una mera exposición de las estrategias de adaptación de los actores considerados individualmente o en grupo; por el contrario, es preciso analizar y entender las relaciones específicas que vinculan a los actores entre sí; las redes humanas de relaciones entre actores existen siempre, pues son la expresión de la vida social, siendo conscientes de que estas redes no son siempre dinámicas y el medio del que forman parte puede bloquear su capacidad de renovación.

De todo ello se deriva el hecho de que en los últimos tiempos los modelos de desarrollo se encuentran sometidos a dos tipos de reflexiones. Por una parte, de naturaleza tanto descriptiva como teórica, sobre la existencia de una heterogeneidad de modelos de desarrollo y la convicción creciente sobre la necesidad de seguir caminos diferentes de desarrollo. Y, por otra parte, la reflexión acerca de la recuperación de la dimensión territorial en el análisis de los procesos económicos. 
Las estrategias de desarrollo diseñadas a partir de las teorías tradicionales vienen siendo objeto de un progresivo abandono, debido principalmente tanto al fracaso de los esquemas de política interregional a nivel nacional para la corrección de los desequilibrio territoriales, como a su falta de capacidad para dar explicación a la emergencia de patrones autónomos de desarrollo en muchas regiones relativamente periféricas (Garafoli, 1992). Por otro lado, se está dejando notar la cada vez más débil movilidad de las empresas (capital) y de la mano de obra (trabajo). elemento clave sobre los que se basaban los enfoques tradicionales.

Estos hechos han ocasionado que se venga produciendo un giro importante en la interpretación del desarrollo regional analizado en apartados anteriores, en favor de un grupo de novedosas aportaciones -de diversa naturaleza, pero con elementos comunesque siguiendo a sus exponentes más destacados, convendremos en llamar "Enfoque del Potencial Endógeno". En este apartado trataremos de mostrar, en forma sintética y que equipara el fundamento de esta orientación teórica, con ramificaciones tan dispersas que hay quien prefiere hablar simplemente de "tentativa de un nuevo paradigma" o de experiencias aisladas, más que de una "teoría" del desarrollo endógeno.

Indudablemente, tras lo hasta aquí expuesto comprobamos que si todas las teorías se nos han presentado en algún momento como directrices a seguir para el logro del desarrollo, en la actualidad se presenta como el eje conductor la relacionada con los modelos de desarrollo local y el desarrollo endógeno; sin embargo, "per se", no llegan a explicar de forma convincente la problemática con la que nos enfrentamos.

Como es lógico, a la hora de confeccionar las distintas fichas, relativas al modelo que se ha seguido o se aplica en un territorio concreto - estado, región,...-, debemos seleccionar aquellas cuestiones que nos parezcan más relevantes, valorando las ideas y cuestiones que puedan llegar a caracterizar dicho modelo, siendo conscientes que la selección de una variables, en no pocos casos, puede entrañar la exclusión de otras (para ello, puede ser de notable interés partir de una bibliografía lo más objetiva y amplia posible). Antes de detenernos en algunos ejemplos concretos queremos significar con el profesor F. Díaz Pineda que en la actualidad se habla, principalmente del modelo de desarrollo sostenible, "sin embargo, no hay este tipo de modelos en ninguna región del mundo. Hay más de treinta definiciones de este concepto, pero no existe ninguna puesta en práctica. Me parece a mí que por dos razones. Primero porque el concepto de desarrollo sostenible no se puede poner en práctica en una provincia dentro de un país o dentro de un país olvidando los de toda una gran región. Esto generaría un problema de competencia importante. Y segundo, porque la democracia participativa es una cosa bastante ausente en la mayoría de los países. Las opiniones de la población en materia de medio ambiente tardan realmente mucho en conocerse y sopesarse para que se lleven a la práctica por parte de la administración"' para añadir, posteriormente, "Aunque he dicho antes que no conocía ejemplos que pudiesen considerarse como extrapolables de desarrollo sostenible, he defendido en otros casos que justamente la cultura mediterránea, por resultarme más inmediata, vivir en ella y conocerla relativamente bien, creo que ofrece, si no ejemplos de aquel concepto, al menos sí marcos excelentes para esta idea (me estoy refiriendo en general a muchas culturas rurales, milenarias, a los ejemplos vivos que hay de conservación de recursos 
de una manera verdaderamente sostenible). Pero, claro, el desarrollo sostenible tendría que aportar un modelo que fuese extrapolable a todo el mundo, de la misma forma que lo ha sido ese otro concepto de desarrollo no sostenible que está dando lugar a tantos problemas ambientales. Se cuenta hoy con una tecnología más capaz que la tradicional, pero falta el arraigo de una conciencia ambiental.

Entre otros objetivos, un modelo de desarrollo sostenible debe conservar la diversidad, la diversidad de paisajes, la diversidad de cultura y la diversidad biológica. Curiosamente, en el mundo desarrollado la gente está perdiendo la cultura de la diversidad. Antes, Emest von Weizsáker y William Clark se han referido a otros tipos de diversidad. A mí me consta que el ama de casa cuando va al mercado termina comprando una lata de almendras de determinada marca convencida en su subconsciente de la actual capacidad de la tecnología que lo resuelve todo: la máquina que fabrica las almendras debe funcionar perfectamente porque todas las almendras son iguales. Ha perdido la cultura mediante la cual, habíamos aprendido a cultivar muchísimas razas y variedades de almendras. Y lo mismo ocurre con otros productos alimentarios. Cuando recorres el campo, encuentras docenas y docenas de variedades de manzanas, almendras, trigos, etc., que se están perdiendo porque el mercado impone sus reglas"

El desarrollo sostenible debería inspirarse en algo ya viejo bajo el sol y que quizás no sea perfecto (el hombre tecnológico lo consideraría así porque representa un ejemplo de la existencia de circuitos de regulación local de la economía), pero que puede ser complementado eficazmente con la moderna tecnología" (Díaz Pineda, F. 1996).

\subsection{TRANSFORMACIONES EN LOS MODELOS, CON BASE EN CATÁSTROFES AMBIENTALES}

La catástrofe del Prestige - en la actualidad, paradójicamente, olvidada- fue el resultado de un modelo energético insostenible en el que la industria del petróleo opera a escala planetaria y minimizando costes como principal objetivo, a costa de un elevado impacto ambiental. Ejemplifica perfectamente los efectos más perversos de la globalización neoliberal sobre el medio ambiente, con especial repercusión en las áreas costeras. Sin embargo, el movimiento ecologista quiere destacar que todo lo relacionado con el Prestige no fue un accidente. Es el resultado de un modelo energético concreto, de un sistema económico guiado únicamente por el beneficio a corto plazo, y cuyos efectos fueron posteriormente maximizados por una Administración pública que dio la espalda al medio ambiente en todo momento.

En los tanques del Prestige, hundido a 130 millas de la costa y a unos 3.800 metros de profundidad, en una zona de cierto riesgo sísmico, están almacenadas aún unas 1400 toneladas que suponen una amenaza real para la costa

Según las autoridades, unas $75.000 \mathrm{Tm}$ de fuel fueron retiradas del mar y de las costas, mezcladas con algas, arena, piedras, plásticos, etc. El acuerdo entre la Xunta y el Gobierno central sobre el sistema de gestión para estos residuos poco contribuye a clarificar la solución, ya que se prevé únicamente la separación de los materia- 
les ajenos al fuel, plásticos en primer lugar, y arena y agua después, para obtener lo que se denomina un fuel "reciclado y dispuesto para su utilización".

Los estudios epidemiológicos se iniciaron muy tarde. No se realizaron mediciones atmosféricas ni se analizaron, durante los primeros meses, los metabolitos de hidrocarburos en las personas afectadas.

Aunque ya han pasado algunos años deberían realizarse análisis permanentes alimentarios completos, especialmente en moluscos bivalvos, incluyendo HAP y metales pesados, haciéndose públicos, posteriormente. Estos análisis se deben hacer públicos.

Por otra parte, las tareas de limpieza mostraron la utilización de las máquinas hidrolimpiadoras se ha hecho en muchos casos sin respetar el protocolo de actuación del propio Ministerio de Medio Ambiente, causando un impacto global importante en las comunidades supramareales e intermareales. El Parque Nacional MarítimoTerrestre de las Islas Atlánticas, el Parque Natural del Complejo Dunar de Corrubedo y Lagunas de Carregal y Vixán y otras zonas de alto valor ecológico propuestas para formar parte de la Red Natura 2000 (Monte y Laguna de Louro, Carnota-Monte Pindo, Costa da Morte, Costa Ártabra,...) sufrieron un importante impacto negativo adicional al causado por las mareas negras, debido a la ejecución ambientalmente inadecuada de los trabajos de recogida del fuel.

En no pocos casos, los daños al medio natural causados por estas desde su inicio fueron muy importantes, siendo escandalosa la falta de sensibilidad y el desconocimiento de los valores del medio natural, o la inhibición en su defensa, exhibido por las diversas administraciones. Es imprescindíble que los protocolos establecidos se cumplan adecuadamente por todas las personas implicadas en las tareas de extracción de fuel y que no se agraven los daños causados por la recogida de fuel. Posteriormente, se mostró imprescindible el inicio de las labores de recuperación ambiental que contrarresten los daños provocados por las tareas de limpieza: restauración de zonas dunares, eliminación de pistas de acceso y restauración ambiental de su trazado, etc.

Por otra parte, la aparente normalidad se consiguió trasladar también a la pesca. En estos cinco años hay ya indicios de efectos sobre algunos recursos concretos, como puede ser el percebe o el mejillón, donde la disminución de individuos juveniles hace prever problemas en el reclutamiento. Este problema puede estar sucediendo con otras especies. Fondos someros, de gran importancia para la cría de muchas especies y vía de entrada de contaminantes en la red trófica, están aún afectados por el fuel. La apertura de la actividad extractiva fue en muchos casos precipitada.

Desgraciadamente poco hemos aprendido sobre los efectos a medio y largo plazo sobre nuestros ecosistemas y nuestra economía de las múltiples mareas negras que ha sufrido España y Galicia en el pasado, la última en 1992. El caso del Prestige, dada su magnitud, debe ser un punto de inflexión en este sentido. Es fundamental que se investigue en profundidad la incidencia de la catástrofe en los ecosistemas litorales y marinos afectados, sobre todo en lo relativo a las especies protegidas que deberían estar ya sujetas a Planes de Conservación. La investigación debe incluir el impacto a largo plazo sobre su funcionamiento integral y no únicamente sobre aquellos recursos naturales de interés comercial. La investigación no se debe limitar a estudiar el impac- 
to sobre el medio biofísico de la catástrofe, sino que debe considerar también el impacto social, cultural, económico y demográfico en las zonas afectadas.

Igualmente, es muy importante que la investigación se dirija no sólo a conocer los impactos del accidente sino que se oriente también a la recuperación de los ecosistemas y las comunidades humanas afectados. Los resultados de todas estas investigaciones deben ser en todo momento públicos.

Desde una perspectiva económica, se planteó El Plan Galicia, que de haberse aplicado en su totalidad, hubiera promovido un modelo de desarrollo ecológicamente insostenible, mostrándosenos insuficiente para garantizar la recuperación ambiental y socioeconómica de las zonas más afectadas por la marea negra y del conjunto de Galicia. El Plan Galicia, que destinó el 96,7\% de su presupuesto a infraestructuras de transporte, representa una nueva marea destructora del medio ambiente, en este caso no de fuel sino de hormigón y asfalto. La construcción de nuevas autovías y vías de alta capacidad, de trenes de alta velocidad estricta $(350 \mathrm{~km} / \mathrm{h})$, del puerto exterior de A Coruña, de los 24 embalses previstos en el Plan Hidrológico de GaliciaCosta... provocó un fuerte impacto ambiental negativo y ha supuesto una elevada inversión económica pública, socialmente poco rentable.

Resulta paradójico que la marea negra del Prestige haya sido la causa de un Plan que apuesto por un modelo de transporte energéticamente ineficiente y fuertemente dependiente del petróleo, modelo que está en el origen de las mareas negras y de otros graves problemas ambientales como el cambio climático global.

En definitiva, las Administraciónes y la sociedad deberían entender la catástrofe del Prestige como una llamada de atención sobre los efectos ecológicos y sociales de una economía insostenible y como una oportunidad para trabajar seriamente a favor del medio ambiente, dada su relación directa con el bienestar y con la calidad de vida. Por ello debería realizarse una evaluación ambiental estratégica analítica, sino del Plan Galicia, ya superado, sí de sus consecuencias, que deberían haberse dirigido más hacia la búsqueda de un modelo de desarrollo ecológicamente sostenible y socialmente más justo, habiendo dedicado mayor atención a la protección y recuperación ambientales, al fortalecimiento del transporte colectivo (especialmente en las áreas metropolitanas), o a aumentar el esfuerzo en $\mathrm{I}+\mathrm{D}+\mathrm{i}$.

Sin embargo, no debemos olvidar que uno de los elementos más positivos en la evolución de la catástrofe ha sido el nivel de conciencia y compromiso ambiental en defensa del mar de la ciudadanía que se ha puesto en evidencia. La respuesta de los 200.000 voluntarios y voluntarias, la autoorganización de los colectivos más afectados, las manifestaciones masivas de protesta, etc. son ejemplos que desvelan una ciudadanía democrática y madura, que quiere participar desinteresada y activamente en aquellos asuntos públicos que le atañen directa o indirectamente.

Es preciso, por tanto, dar una respuesta adecuada a los niveles de conciencia y acción ambiental puestos de manifiesto en ésta y en otras crisis. Para ello es preciso desarrollar programas y materiales educativos y formativos que faciliten a la población un conocimiento más profundo de lo sucedido, que destaquen la estrecha interdependencia entre ambiente y calidad de vida, y que actúen como barreras culturales 
en previsión de futuras calamidades. Así mismo, es preciso apoyar la labor social y educativa de los colectivos ciudadanos y las organizaciones ambientalistas que tienen entre sus objetivos la construcción de una sociedad democrática abierta y sostenible. En este sentido, es necesario impulsar de una vez por toda la educación ambiental en Galicia, aplicando íntegramente la Estrategia Gallega de Educación Ambiental aprobada en 1999

\section{A MODO DE CONCLUSIONES}

Tras lo hasta aquí expuesto podemos llegar a las conclusiones siguientes:

Primera Conclusión: Convenio de Kioto, deshielo de casquetes polares, huracanes tropicales. A veces, los efectos del calentamiento del planeta suenan lejanos. Pero los trastornos están a nuestro lado. La naturaleza que nos rodea cambia. Aves, plantas e insectos se comportan de modo distinto. Éste es el cambio climático cotidiano, en el patio de nuestra casa

Segunda Conclusión: El coste de la lucha contra el calentamiento global va a ser muy elevado - cerca de cinco billones de euros-- La reducción de emisiones de $\mathrm{CO}_{2}$ es enormemente costosa y muy poco productiva, pues deberíamos dedicar nuestro esfuerzo y dinero a ir aligerando, poco a poco, las emisiones futuras de gases efecto invernadero. Esto significaría potenciar la investigación, al desarrollo de la energía solar, de la fusión,...

Tercera Conclusión: Debemos estar abiertos a nuevos logros tecnológicos (v.gr: geoingeniería). Así, iríamos desde fertilizar el océano (para que las algas capturen el carbono cuando mueren) a colocar partículas de azufre en la estratosfera (para enfriar el clima) o a capturar el $\mathrm{CO}_{2}$ de los combustibles fósiles y llevarlos a almacenes geológicos.

Cuarta Conclusión: No son pocos los territorios de nuestro país, en general, en los que los cambios en los modelos de desarrollo, con amplias repercusiones no sólo económicas, sino también sociales e incluso políticas, se están dando a partir diversas catástrofes ambientales.

Quinta Conclusión: Deberían plantearse y generarse importantes cambios en la política energética, pues resulta un despropósito que en tras de la catástrofe del Prestige se haya mantenido una política que impide, cuando menos que España cumpla los compromisos asumidos del Protocolo de Kioto. Por lo tanto, debería primarse una política energética basada en el ahorro, la eficiencia y las energías respetuosas con el medio ambiente, como solución última a los impactos ambientales derivados del uso y transporte de combustibles fósiles a escala global, todo ello en paralelo a una política de transporte que potencie los modos de transporte más eficientes energéticamente y limite el uso del automóvil privado.

Sexta Conclusión: Debería acabarse con la responsabilidad ilimitada de las empresas: Como en el caso del Prestige, las industrias sucias trasladan los costes económicos de la degradación medioambiental al conjunto de la sociedad. Esta catástrofe fue el resultado también de lo "barato" que resulta contaminar y de lo fácil que es obviar el riesgo para maximizar los beneficios económicos. El hecho de que el Fondo de Indemnización Internacional para hacer frente a las indemnizaciones derivadas de 
la contaminación por hidrocarburos provocada por los accidentes marítimos haya ascendido de 175 a 1.000 millones de euros es un avance pero no es suficiente, el Prestige supuso a los ciudadanos unas pérdidas económicas de entre 900 y los 10.000 millones de euros.

Séptima Conclusión: Debe, por tanto, buscarse un régimen de responsabilidad ilimitada para toda la cadena involucrada en el transporte de hidrocarburos, desde el armador al propietario de la carga, incluyendo a las aseguradoras y las sociedades de clasificación. Todo buque que transporte estas sustancias debe estar en posesión de un seguro que cubra sin límite la cuantía de los daños ocasionados por un accidente. Estos costes deben incluir no sólo el impacto directo sobre los ecosistemas sino también los costes de su recuperación. Todo ello, unido a la creación de seguros que se apliquen a las áreas naturales protegidas.

Octava Conclusión: Ha de propiciarse cambios en la política de transporte marítimo: Si algo puso de manifiesto la marea negra del Prestige (en los prolegómenos del actual siglo) es que en las últimas décadas la UE apenas ha avanzado en seguridad marítima. Pese a que las costas europeas han sido escenario de numerosas catástrofes de esta índole, no ha sido hasta el accidente del Prestige que las medidas incluidas en los paquetes de medidas Erika I y II han ido siendo aprobadas. Además, son claramente insuficientes para garantizar que un accidente como el del Prestige no vuelva a suceder, pero esto no va a suponer grandes cambios en el modo de operar de la industria. Por otro lado, los calendarios de eliminación de buques monocasco de estos paquetes son también insuficientes. Entre los cambios podemos destacar: la prohibición del transporte de hidrocarburos y sustancias peligrosas en general en buques de casco simple; la creación de una red de infraestructuras con todos los medios necesarios para responder a un accidente de estas características; mejorar las inspecciones; la declaración de Áreas Marinas Especialmente Sensibles (AMES). En este sentido damos la bienvenida a la propuesta realizada por 6 Estados Miembros de la UE de declarar la fachada atlántica europea, incluyendo Galicia, como AMES por parte de la Organización Marítima Internacional (OMI), aunque nos preocupa la falta de medidas acompañantes para mejorar la seguridad marítima que hagan eficaz dicha designación, así como la oposición de diversos países a que esta propuesta se haga realidad. Es igualmente necesario un acuerdo en el contexto de la ONU y agencias relacionadas para resolver el problema de los pabellones de conveniencia. La UE debe jugar un papel clave en este proceso.

Novena conclusión: Deben realizarse nuevos Planes así como dotarse de medios de lucha contra la contaminación. Es más que sorprendente la falta de medios de prevención y lucha contra la contaminación en una de las áreas con tráfico marítimo más intenso del mundo y con un historial de catástrofes marítimas como es el caso de las costas gallegas. Una vez más, las administraciones públicas españolas han quedado en entredicho, no habiendo servido todos los accidentes anteriores para dotarse de los medios más básicos para enfrentarse a una catástrofe como la padecida. Es, igualmente, muy grave la ausencia en la práctica de protocolos o planes de contingencia, pese a sí existir en el papel. La consecuencia ha sido la ampliación del abanico de litoral afectado al arrastrar el barco siniestrado a lo largo de toda la costa gallega, 
alcanzando la contaminación también a las costas del Cantábrico español, Francia y sur de Reino Unido. Cinco años después poco se ha avanzado en este sentido.

Décima Conclusión: Vigilancia y prevención respecto de la contaminación difusa: Durante los últimos años se han constatado públicamente las acciones de empresas y barcos desaprensivos que aprovecharon la situación de contaminación de hidrocarburos en el mar para limpiar sus sentinas al paso por la costa o cuando se refugian de los temporales a las entradas de las rías. Estas acciones, lejos de ser puntuales o circunscritas a los últimos años, son práctica común y aportan nuevas y continuas cantidades significativas de contaminantes al medio marino. Es inexcusable un servicio de vigilancia que disuada y penalice este tipo de acciones, y que debe ser parte de un servicio integral de lucha contra la contaminación.

\section{BIBLIOGRAFÍA}

AGENCIA EUROPEA DE MEDIO AMBIENTE (2010), El Medio Ambiente en la Unión Europea, 2009.

AGENCIA EUROPEA DE MEDIO AMBIENTE, (1998), El Medio Ambiente en la Unión Europea 1995. Informe para la Revisión del Quinto Programa sobre Medio Ambiente, Oficina de Publicaciones Oficiales de las Comunidades Europeas, Luxemburgo.

- (1998), El Medio Ambiente en Europa, Informe Dobris, Oficina de Publicaciones Oficiales de las Comunidades Europeas, Luxemburgo, (Publicado por el Ministerio de Medio Ambiente, Madrid).

- (1997), "Environmental Agreements: Environmental Effectiveness", Environmental Issues $\mathrm{N}^{\mathrm{o}} 3$, Copenhague.

- (1996), "Environmental Taxes", Environmental Issues, Series No 1, Copenhague.

AA.VV. (1991). Metodología para la Incorporación del Medio Ambiente en la Planificación Económica., Junta de Andalucía., pp.70.

ABREU Y PIDAL, J.M. (1975). "El medio natural en la planificación del desarro1lo"., ICONA., Madrid.

ACOSTA, F. (1986). "Modelos"., Revista Ecosistemas., pp. 58-59.

AGUILAR, S. (1997). El reto del medio ambiente. Conflictos e intereses en la política medioambiental europea., Madrid., Alianza Universidad.

AGUILAR, S. Y SLOCOCK, B.(1997). "El reto medioambiental en la Europa Oriental: Las lecciones de Occidente"., Gestión y Administración Pública., n.6.

AGUILÓ, M., GONZÁLEZ ALONSO, S., RAMOS, A. (1995). Directrices y técnicas para la estimación de impactos, 39 edición, Cátedra de Proyectos y Planificación de la E.T.S. de Ingenieros de Montes, Madrid.

ALONSO, J. (1990). La nueva situación regional., Madrid., Editorial Síntesis., 166 págs. ALONSO, C (1996). Variaciones sobre un mundo en cambio. Ed. Alianza. Madrid. $572 \mathrm{pp}$.

ALONSO, J "et alia"(1997). Temas de Geografía de España., Madrid., UNED, $3^{\circ}$.edc. 311 págs. 
ALONSO, L. E. (1999). "El discurso de la globalización y la nueva desigualdad regional"., Estudios Regionales, 54., pp. 125-145.

ALONSO, L .E. (1999). "El discurso de la globalización y la nueva desigualdad regional"., Estudios Regionales, 54., pp. 125-145.

AZQUETA, D., PÉREZ, L., (Eds.) (1996): Gestión de Espacios Naturales. La demanda de servicios recreativos. McGraw-Hill, Madrid

ALLENDE, J.(1995). "Desarrollo sostenible. De lo global a lo local"., Ciudad y Territorio-Estudios Territoriales., n. 104., pp.267-281.

ALlUN, P. (1995). State and Society in Western Europe., Cambridge., Polity Press. ARTIGAS, M (1982): Filosofía de la Ciencia Experimental Pamplona., EUNSA, ATKINSON, G.(1996). "Desarrollo sustentable: teoría, medición y políticas"., ICE, n.751., pp. 15-25.

BANCO MUNDIAL (1988): Informe sobre el DesarrolloMundiaL Las finanzas públicas en el proceso de desarrollo. Washington.

BANCO MUNDIAL (1990): Informe sobre el Desarrollo Mundial. La pobreza. Washington.

BANCO MUNDIAL (1991): Informe sobre el Desarrollo MundiaL La tarea acuciante del desarrollo. Washington.

BANCO MUNDIAL (1993 y siguientes): Informe sobre el Desarrollo MundiaL Invertir en salud. Washington.

BARBARIT, L.M. «et alia».(1990): La nouvelle Vendée, voyage dans la Vendée industrielle.Edt. France-Empire. 257 págs.

BARRAGÁN, J.M.(2004). Las áreas litorales en España: del análisis geográfico a la gestión integrada, Editorial Ariel., 214 págs.

BARRAGÁN, J.M.(2005). La gestión de áreas litorales en España y Latinoamérica., UCA., 198 pp.

BARRAGÁN, J. M “et alii” (2005). Towards Integrated Coastal Zone Management in Chile., Coastal Management, 33., pp. 1-25.

BEAUFAIS, J.(1975). "La notion de region", en L'Europe et ses régions., pp. 267287. Liege., Faculté de droit.

BENKO, G (1990). "La cite-scientifique de 1'Ile de France-Sud"., Annales de Geographie, 556., pp. 660-674.

BRADFORD, C. (1989): «Las nuevas formas que adquieren los mercados mundiales y la naturaleza de la interdependencia en un mercado cada vez más multipolar». Revista de la Sociedad Internacional para el Desarrollo, n.2 15, pp. 58-61.

BERTELMUS, P.(1990): «Sustainable development; a conceptual Framework». Diesa Working Paper Series, New York.

BERZOSA, C. (1991). Los nuevos competidores internacionales. Hacia un cambio en la estructura industrial mundial., Ciencias Sociales., Madrid.

BOIRA, J.V. Y SOUTO, X.M. (1995). Percepción del medio y planificación del territorio: el caso de Vigo., Boletín del la AGE, $\mathrm{n}^{\circ}$ 20., pp. 67-80.

BOISIER, S. (1995). "La modernización del Estado: una mirada desde las regiones (revoluciones, reformas, objetivos nacionales y el papel del territorio)"., Estudios Regionales, $\mathrm{n}^{\circ}$ 41., pp.15-38. 
BOISIER, S. (1997). "En busca del esquivo desarrollo regional: entre la caja negra y el proyecto político"., Ciudad y Territorio, Estudios Territoriales., XXIX, 112., pp. 379-397.

BLACKSELL, M.(1994).«Environmental Policies and Resource Management», en Blacksell, M., y Wifliams, A. M.: The European challenge. Oxford: Oxford Uníversity Press.

BRUNDTLAND, G.R. (1988): Our Common Future. TherReport ofthe Wold Commission on Environment and Development. Oxford University Press.

CABERO DIÉGUEZ, V. (1994). Contribución para la definición de una estrategia de intervención y la promoción

CABERO DIÉGUEZ, V. (1996). Los espacios naturales protegidos: el dilema entre conservación y el desarrollo local., en Dinamismos socio-económicos e (re) organizaçao territorial: procesos de urbanizaçao e de reestructuraçao productiva., Instituto de Estudios Geográficos., Universidad de Coimbra., pp. 501-510.

CABERO DIÉGUEZ, V. (2001). Espacios naturales protegidos y conservación del medio., en GIL OLCINA, A y GÓMEZ MENDOZA, J. (coord.). Geografia de España., Barcelona, Edt. Ariel., pp. 207-221.

CSATÁRI, B (1993). "El programa Alföld: un proyecto experimental de desarrollo regional en Hungría"., en AA.VV. Autonomías y desarrollo. III Seminario HispanoHúngaro sobre Desequilibrios Regionales., UNED., Madrid., pp. 125/152.

CASTELLS, M. "et alia”(1986). Nuevas tecnologías, Economía y Sociedad en España., Madrid., Alianza Edit. 2 vols.

CASTELLS, M. (1999). "El mundo según Davos"., El País., 12 de febrero, pág. 18.

C.E.E. Primer Programa Europeo contra la pobreza (1975-1980).

C.E.E. Segundo Programa Europeo contra la pobreza (1984-1988).

C.E.E. Tercer Programa Europeo contra la pobreza (1 990-1995).

CEPAL. (1997). Resúmenes de Documentos sobre Planificación y Medio Ambiente.

CLUB DE BRUXELLES (1992). "L'Environnement dans le Marché unique europeen"., Vol.1., pp. 61-63.

CORTÉS, R. (1996). "El Programa Español de Desarrollo y Diversificación Económica de Zonas Rurales Objetivo 1"., Baetica., vol. 18., pp.63/72.

CURBELO, J.L. "et alia". (1989). "Los estudios regionales en el contexto anglosajón: ¿"Ciencia regional" vs. "Economía política regional"?"., Estudios Regionales, n. 23., pp. 15-27.

CHESNAIS, F. (1997). La Mondialisation du capital., Paris., Syros., 251 págs.

CHOMSKY, N. (1998). "Finanzas y silencio"., Le Monde Diplomatique., diciembre., pp. 15.

DALY, H.E. (1996). "Desarrollo sostenible y escala óptima de la economía"., en Díaz Pineda, F. (editor). Ecología y Desarrollo., Madrid., Edit. Complutense., pp. 73-84.

DEPARTAMENTO DE PROYECTOS Y PLANIFICACIÓN RURAL.(1994). Casos prácticos en la Planificación fisica y Evaluación de Impactos. Fundación Conde del Valle de Salazar, E.T.S. de Ingenieros de Montes, Madrid.

DÍAZ PINEDA, F. (1996). "Desarrollo sostenible y escala óptima en la economía"., en Díaz Pineda, F. (edt.). Ecología y Desarrollo., Madrid., Edt. Complutense., pp. 73-76. 
ENKERLIN HOEFLICH, E (1997). Ciencia Ambiental y Desarrollo Sostenible Internacional. Thomson Editores. $666 \mathrm{pp}$.

ESCOBAR GÓMEZ, G.(1994). "Evaluación de Impacto Ambiental en España: resultados prácticos"., CyTET, II (102)., pp.585-593.

ESTEBAN MORATILLA, F. (1999). "La Ordenación del territorio en la perspectiva de la construcción europea"., en Jornadas Técnicas de Debate sobre Oportunidades y problemas de la Ordenación del Territorio., Sevilla., 24-26 de febrero.

ESTÉBANEZ, J. (1996). "Barreras que dificultan la comprensión del espacio en la etapa de acumulación flexible" (en prensa).

FMI (2000). World Economic Outlook.

FONT, N.(1996). La europeización de la Política Ambiental en España. Un estudio de implementación de la Directiva de Evaluación de Impacto Ambiental., Universidad Autónoma de Barcelona.

FREEMAN, CH. ET ALIA. (1985). Desempleo e innovación tecnológica. Un estudio de las ondas largas y el desdarrollo económico., Madrid., Ministerio de Trabajo y Seguridad Social.

FRIEDMAN, J. (1979). Territory and Function., University of California Press.

FURIÓ, E. (1994). "El desarrollo económico endógeno y local: reflexiones sobre su enfoque interpretativo"', Estudios Regionales, no 40., pp.97-112.

GARCÍA ALVARADO, JOSÉ Ma (1997). "Propuesta teórico-metodológica para la valoración de la calidad urbano ambiental"., Anales de Geografía de la UCM., $\mathrm{n}^{\mathrm{o}}$ 17., pp. 11-26.

GARCÍA ALVARADO, JOSÉ M" (2000). "El modelo metropolitano madrileño: enjuiciamiento desde la perspectiva del V Programa de Acción de CE. En materia de Medio Ambiente. Apuntes metodológicos"., Observatorio Medioambiental., no 3., pp. 135-158.

GARCÍA BALLESTEROS, AURORA (1998)., "Nuevos espacios del consumo y exclusión social"., Anales de Geografía de la UCM., n $18 .$, pp. 47-53.

GARCÍA DE ENTERRÍA, E. (1997). "Economía y secularización de la política"., Madrid., ABC., 27 de noviembre.

GARRIDO, A. "et alia" (1996), "Estudio del uso y valoración del parque regional de la Cuenca Alta del Manzanares (Madrid) mediante el método del coste de viaje", en Azqueta, D. y Pérez y Pérez, L. (Eds.),

GÓMEZ-SAL, A. (1998). "Valoración multicriterio a escala local"., Ecosistemas., n.24-25., pp. 41-47.

GOODLAND, R.(1997). Medio Ambiente y Desarrollo Sostenible: más allá del informe Brundtland. Ed. Trotta, D.L. Madrid. 133 pp.

GONZÁLEZ BERNÁNDEZ, F. (1976). "Problemas ecológicos de la conservación del medio ambiente"., en AA.VV. Conservación del medio ambiente., Revista de la UCM., vol. XXV, n.105., pp.165-173.

GONZÁLEZ, M. (1997): Valoración económica del uso recreativo-paisajístico de los montes: aplicacion al Parque Natural de Monte Aloia en Galicia. Tesis Doctotal, Departamento de Economía Aplicada, Facultad de Ciencias económicas y Empresariales Universidad de Vigo. 
GONZÁlEZ, E (2001). De los tajos a los embarcaderos., Barcelona., Edt. Ariel., 320 págs.

GREFFE, X (1988). Descentralizar a favor del empleo. Las iniciativas locales de desarrollo., Madrid., Ministerio de Trabajo y Seguridad Social.

GREENPACE (2011). The international trade in wastes. A Greenpace inventory., Washington.

GUTIERREZ, J.(1998). Redes, espacio y tiempo., Anales de Geografía de la UCM., $\mathrm{n}^{\mathrm{o}} 18 .$, pp. 65-86.

HAGGET, P., y CHORLEY, J.(1967). "Models, paradigms and the new geography"., in AA.VV. Models in Geography., pp. 19/41.

HALIMI, S. (1998). "El naufragio de los dogmas liberales", Le Monde diplomatique.

HEREDIA, R. DE (1987). "Concepto y diseño del Parque Tecnológico de Madrid"., Madrid., Heredia-Consultores.

HIERNAUX, D. (1995). "La región insoslayable"., Revista Eure, 63., Universidad Católica de Chile., Instituto de Estudios Urbanos.

HIGGINS, B. (1995). "Regional Development Theories and Their Applications".

HOPENHAYN, M (1994). "Ni apocalípticos ni integrados. Aventuras de la modernidad en América Latina"., Santiago de Chile., F.C.E.

INSTITUTO TECNOLÓGICO Y GEOMINERO DE ESPAÑA.(1997). Los peligros naturales de España en 1994. Ministerio de Medio Ambiente, 63 pp.

INSTITUTO TÉCNOLÓGICO Y GEOMINERO DE ESPAÑA.(1998). Guía visual para la evaluación y corrección de impactos ambientales. Ed. IGME. Madrid.

JIMÉNEZ-HERRERO, L. (1989). Desarrollo y Medio Ambiente. Alianza Edt. Madrid. JIMÉNEZ HERRERO, L. (1996). Desarrollo Sostenible y Economía Ecológica., Madrid., Edt. Síntesis.

MYERS, N. (1989): GAL4, An Atlas of Planet Management. London, Gaia Book limited. MORALES MATOS, G. (1986). El grupo humano en el espacio geográfico asturiano. MORALES MATOS, G, (director) (1993). Geografía de Canarias., Prensa Ibérica., 2 tomos., Las Palmas de Gran Canarias.

KAUL, I.(1996). The Tobin Tax: Coping with Financial Volatility., Oxford U.P.

LÁZARO ARAUJO, J. (1977). "Modelos de desarrollo regional"., ICE., juniojulio.,pp.14-40.

LEE, N. (1991).Quality control in the EIA process.EIA Newsletter 6:22-23.

LILLIAN, T «et alia» (1977): «Urbanization -Industrialization andthe Theory of Demographic Transition». Pacific Sociological Review, vol. 20. ni' 1. pp.1 13-134.

LEÓN, C. (1994): La valoración contingente del paisaje de los parques naturales del centro-occidente de Gran Canaria, Tesis Doctoral, Departamento de Economía Aplicada. Universidad de las Palmas de Gran Canaria.

LÓPEZ LÓPEZ, ALEJANDRO (2000). "Requisitos medioambientales para un programa de acción sobre Turismo Rural en la Comunidad Autónoma de Madrid"., Observatorio medioambiental., $\mathrm{n}^{\circ}$ 3., pp. 195-222.

MAESTRE, L. (1992). "Política Medioambiental en España. Estado y Autonomías"., en Revista 3Economía4., n.14., pp. 58-62.

MARGALEF, R. (1990): «La diversidad biológica y su evolución». Panda, n. 8. pp.4-18. 
MARTÍN, M.A., RAMOS A., VELARDE, M.D. (Eds.).(1994). Papeles del Centro EIA. Cátedra de Proyectos y Planificación de la E.T.S. de Ingenieros de Montes, Madrid. MARIÑO, F.M. (1993). "La configuración progresiva de la Política Medioambiental Comunitaria"., C.E.C., pp. 799-835.

MATH,M (1993): «Population problems: constituen of general culture in the 21 century».International Review of Education. 39 (1-2), pp.5-13.

MAURER, J.L. (1995). "La economía de Indonesia"., Rev. Estudios Asiáticos., no 1., pp. $51 / 78$.

MAGADÁN, M., RIVAS, J., (1998), Economía Ambiental: Teoría y Políticas, Editorial Dykinson, Madrid.

MAGARIÑOS, ANTONIO (1999). "La Información Ambiental: viejas necesidades, nuevas demandas y soluciones pendientes"., Madrid., Academia de las Ciencias,..., "Homenaje a D. Ángel Ramos"., pp. 1395-1414.

MANZINI, E.(1996): Artefactos: hacia una nueva ecología del ambiente artificial. Ed. Celeste. Madrid. 206 pp.

MÉNDEZ, R. "et alia" (1998). "Procesos de industrialización periférica y espacios emergentes en Castilla-La Mancha"., Anales de Geografía de la UCM., $\mathrm{n}^{\circ} 18$. , pp. 177-204.

MINISTERIO DE MEDIO AMBIENTE. ESPAÑA.(1996). Seguimiento de la contaminación producida por el accidente del buque Aegean Sea. Ed. Ministerio del Medio Ambiente, Centro de Publicaciones. Madrid. 185 pp.

MINISTERIO DE MEDIO AMBIENTE. ESPAÑA.(2000). Haciendo camino hacia el desarrollo sostenible en España. Ministerio de Medio Ambiente. Centro de Publicaciones. 63 pp.

MITCHEL, R.C., "et alia". (1989): Using Surveys to Value Public Goods: The Contingent Valuation Method, Resources for the Future, Washington, D.C.

MEADOWS, D.H. «et alia». (1972): Limits to Growth. New York. Universe Books. MEADOWS, D.H. (1996). "Más allá de los límites"., en Díaz Pineda, F.(editor). Ecología y Desarrollo., Madrid., Editorial Complutense., pp. 57-73.

MENARD, S «et alia» (1987): Perspectives on population.An introduction to concepts and Issues, Oxford - New York. Oxford University Press.

MORALES MATOS, G. (1986) El grupo humano en el espacio geográfico asturiano., Servicio de publicaciones de la Universidad de Oviedo, Oviedo.

MORALES MATOS, G. (dir.). Geografia de Canarias., Prensa Ibérica., 2 tomos., Las Palmas de Gran canarias.

MORTIMORE, M. (1992). "El nuevo orden industrial internacional”., en Revista de la CEPAL., $\mathrm{n}^{\circ} 48$.

MOSS, R.H. «Research on global change and its human dimensions». IGBP Newsletter, 9. pp.12-15.

MUÑOZ, J.(1992): «Perspectiva ambiental e integración disciplinar en Geografía», Boletín de la A. G.E. n. 14, pp. 1-6.

MUÑOZ, R. (coord.). Crisis y futuro del Estado de Bienestar. Madrid, Alianza Universidad.

NAREDO, J.M. (1987). La economía en la evolución., Siglo XXI. 
NAREDO, J.M. (1998). “¿A dónde va a parar la crisis?”., Le Monde Diplomatique., octubre., pág.2.

NOIN, D.(1983): La transition démographique dans le monde. Paris, P.U.F.

ODUM, H. (1980): Ambiente, energía y sociedad. Barcelona. Edt. Blume. 410 págs.

PAZ, M.A. de (1998). Economía mundial., Madrid., Edt. Pirámide., 605 págs.

PÉREZ VILLAR, M. (1990). "Perspectivas de Desarrollo Económico en Castilla y León"., en Actas del Primer Congreso de Economía Regional de Castilla y León., pp. 12-50.

PÉREZ DÍAZ, V.(1996). Política y economía del agua en España: criterios, alternativas y proceso de aprendizaje. Madrid. Círculo de empresarios. $158 \mathrm{pp}$.

PERIS MORA, EDUARDO.(1997). Contaminación y uso del litoral de las costas de España. Ed. Universidad politécnica de Valencia, Departamento de ingeniería de la construcción. Valencia.

PÉREZ, L. "et alia" (1996a): "El Valor de Uso Recreativo del Parque Nacional de Ordesa y Monte Perdido: Coste de Viaje versus Valoración Contingente" en Azqueta, D. y Pérez y Pérez, L. (Eds.)

PÉREZ, L., "et alia". (1996b):"La valeur d'usage á des fins de loisir des espaces protégés en Espagne. Comparision entre méthode des cóuts de déplacement et méthode d'evaluation contingente". Cahiers d 'Economie et Sociologie Rurales, $n^{\circ} 41$, pp. 40-5 6 .

POOLE, M.(1989): Protección del Medio Ambiente en los proyectos de gasoductos. Barcelona. SEDIGAS.

PRECEDO, A. (1994). Desarrollo territorial y planificación comarcal., Xunta de Galicia., Santiago de Compostela., 190 págs.

PRERA FLORES, A. (1998). “¿Sociedad de mercado? No, gracias”., El País., 27 de agosto.

PUYOL, R. (1982): Población y espacio. Problemas demográficos mundiales. Madrid. Edt.Cincel.

PUYOL, R. (1984): Población y recursos. El incierto futuro. Madrid. Edt. Pirámide.

RAMONET, IG (1998). "El fracaso de los dogmas neoliberales"., Le Monde Diplomatique., diciembre., pág. 18.

RAMOS, A. «et alia» (1979): Planificación física y ecología. Modelos y métodos. Madrid.Edt. E.M.E.S.A.

RAMOS, A. (edt) (1987): Diccionario de la naturaleza. Hombre, ecología y paisaje. Madrid. Espasa-Calpe.

RAMOS, A. (coordi.) (1990): «Medio Ambiente y crecimiento económicos. Revista del Instituto de Estudios Económicos, $\mathrm{n}^{\circ} 2$.

REBOLLEDO, D., "et alia" (1994): "Valoración contingente de bienes ambientales: aplicación del Parque Natural de la Dehesa del Moncayo ", Documento de trabajo 94/6, Servicio de Investigación Agraria, Unidad de Economía y Sociología Agrarias, Diputación General de Aragón, Zaragoza.

RECREO JIMÉNEZ, F.(1997).Consideración del cambio medioambiental en la evaluación de la seguridad: escenarios climáticos a largo plazo en la Península Ibérica. Publicación Técnica ENRESA. 110 pp. 
RIERA, P. (1994): Manual de valoración contingente, Instituto de Estudios Fiscales, Madrid.

RIERA, P., "et alia" (1994): "El valor de los espacios de interés natural en España. Aplicación de los métodos de la valoración contingente y el coste del desplazamiento". Revista Española de Economía, n monográfico "Recursos Naturales y Medio Ambiente", Pp.207-230

RIVAS, DAVID. M.(1997). Sustentabilidad: desarrollo económico, medio ambiente y biodiversidad Ed. Parteluz. Madrid.

RODRÍGUEZ PORRAS, JAVIER.(1989). Problemas de contaminación ambiental: causas y rasgos distintivos en Madrid capital. Madrid. Ayuntamiento.

RODRÍGUEZ SÁIZ, L., (1988), "Política Económica y Medio Ambiente", Revista Comunidad Educativa, ICCE, $\mathrm{N}^{\circ}$ 158, Educación Ambiental, Madrid, págs.14-16.

RODRÍGUEZ, P.J. (2000). "Aproximación a los diversos Programas de Acción Comunitaria en materia de Medio Ambiente"., Observatorio Medioambiental., $\mathrm{n}^{\mathrm{o}}$ 3., pp. 455-488.

ROMERO, J. Y PÉREZ, J.(1992): Pobreza y desigualdad en los países en desarrollo. Madrid. Edt. Síntesis.

ROMERO, J. «et alia».(1992): Desigualdades y nueva pobreza en el mundo desarrollado.Madrid. Edt. Síntesis.

ROSAS, C.A. (2007). Sumideros de carbono: ¿solución a la mitigación de los efectos del cambio climático? Revista Ecosistemas.

RUNYAN, C. (1999). "La crisis de Indonesia"., Ecología World-Watch., nº 6., pp. 10/40.

RUESGA, S.M. (1991): «Reflexiones preliminares sobre la evaluación monetaria del Medio Ambiente». Rev. Situación, W 2. pp. 155-162.

RUIZ ELVIRA, A.

SÁNCHEZ, J. "et alia" (coord.). II Seminario Hispano-Húngaro sobre desequilibrios regionales"., Madrid-La Rioja., 7-12 de octubre.

SANTOS, M. (1973): Geografía y economía urbanas en los países subdesarrollados. Barcelona. Oikos-Tau.

SANTOS, M. (1988): «Nuevo orden internacional y reorganización espacial». Urbanización, Subdesarrollo y crisis en América Latina. Seminario de Geografía. Albacete. pp. 27-34.

SANTOS, M. (1993). Los espacios de la globalización., Madrid., Anales de Geografía de la Universidad Complutense., $\mathrm{n}^{\circ}$ 13., pp. 69-80.

SAUVY, A.(1973): ¿Crecimiento cero? Barcelona. Edt. Dopesa. 255 págs,

SANZ, J.J. Y GARCÍA RODRÍGUEZ, MA P.(1991): «Desertificación, erosión y degradación de suelos». Rev. Situación, ng 2. pp. 55-71.

SANZ FONFRÍA, RAMÓN.(1989). Ingeniería ambiental: contaminación y tratamientos. Barcelona. Marcombo Boixareu Editores, $145 \mathrm{pp}$.

SEBASTIÁN, L. DE (1988): La crisis de América Latina y la deuda externa. Madrid. Alianza Editorial

SEOÁNEZ CALVO, MARIANO.(1996). Ingeniería del medio ambiente aplicada al medio natural continental: la contaminación del medio natural continental: aire, 
aguas, suelos, vegetación y fauna. Tecnologías de identificación, lucha y corrección. Ed. Mundi-Prensa: Análisis y trabajos prospectivos. Madrid. $701 \mathrm{pp}$.

SOLER, MANUEL A.(1997): Manual del Gestión del Medio Ambiente. Ed. Ariel. Barcelona. $475 \mathrm{pp}$.

SUÁREZ , JOSÉ LUIS (1997). El Nuevo Plan General de Ordenación Urbana de Madrid: oportunidades para los operadores urbanos. Ed. IESE: Caja de Madrid. Ayuntamiento de Madrid. $454 \mathrm{pp}$.

SEMPRÚM, J. (1998). Geopolítica del hambre, 1998/1999., Madrid, ACH.

SEVILLA, J. (1999). "Dinámica de pobres y ricos”., El País., 9 de enero., pág. 12.

SHAW, R.P. (1992): «Environment Impact». Assessment Review. marzo-junio.

SIMÓN, J. (1 98 1): The Ultimate Resource. Princeton, Princeton University Press.

SIMÓN, J. y KAHN, H.(1984): TheResourcefulEarth. New York. Basil Blackwell Inc.

SOLDEVILLA, E. (1991). "La política medioambiental de la Comunidad Europea"., Rev. Situación., n.2., pp. 163-176.

SOTELO NAVALPOTRO, JUSTO (1995)., Economía Española: Los Marcos Sectorial y Social, Editorial Mapfre, Fundación Mapfre Estudios, Instituto de Ciencias del Seguro, Colección Universitaria, Madrid.

SOTELO NAVALPOTRO, JUSTO Y ALGARRA, A.A.(1999). "Política Económica y Medio Ambiente"., Observatorio Medioambiental, no 2., pp. 311-330.

SOTELO NAVALPOTRO, JOSÉ ANTONIO (1998). "Los contextos de la Política Ambiental Española actual: adaptación del Quinto Programa de la U.E."., Observatorio Medioambiental., $\mathrm{n}^{\mathrm{o}}$ 1., pp. 127-140.

SOTELO NAVALPOTRO, JOSÉ ANTONIO (1998). "Medio Ambiente y Desarrollo en la España de los noventa: la problemática regional de los residuos tóxicos y peligrosos", Anales de Geografía de la UCM., n 18., pp. 257-280.

SOTELO NAVALPOTRO, JOSÉ ANTONIO (1999). Modelos de Organización y Desarrollo Regional., Madrid., IUCA. 195 págs.

SOTELO NAVALPOTRO, JOSÉ ANTONIO (2000). Regional Development Models., Oxford University Press.

SOTELO NAVALPOTRO, JOSÉ ANTONIO (2000). Medio Ambiente y Desarrollo en España en los prolegómenos del siglo XXI: Las Políticas Medioambientales de la U.E.", Observatorio Medioambiental., n 3., pp. 341-397.

STÖHR, W.B. (1986). "La politique japonaise des technolopes: Innovation Technologique et industrielle"., en Federwich, J. "et alia". "Technologie nouvelle et ruptures regionales"., Paris., Económica., pp. 123/139.

SOLOZÁBAL, J.M ${ }^{\mathrm{a}}$. (1989). Curso de Economía., Bilbao., Edt. Deusto.

SURENDRAN, M (1992): «Medio Ambiente y Subdesarrollo». en VV.AA. Guía de acción joven sobre desarrollo sostenible». Madrid, AIESEC.

TAMAYO-ACOSTA, J.J. (1999). "El cristianismo en tiempos de globalización"., El País, 4 de enero, pág. 12.

TAMAMES, R. (1 977): Ecología y Desarrollo. Madrid. Alianza Edt.

TAMAMES, R. (1989).Pobreza, penuria y subdesarrollo. Documentación Social, n. 76. pp.33-41.

TODARO, M.P. (1 989): «Economic Development in the Third World». New York, 41 edc. Longman Inc. 
TOLEDO, V.M. 1987. Ecología y autosuficiencia alimentaria. México: Siglo XXI.

TOLEDO, V.M. 1993. Ecología y nueva Ley Agraria en México: preludio y fuga de una modernización obsoleta. Alternativas para el Campo Mexicano. México: Fontamara.

TORRES LUNA, Ma . P. "et alia”. (1990). Galicia., rexión de contrastes xeográficos., Universidade de Santiago de Compostela., 210 págs.

TORRES LUNA, Ma.P."et alia" (Editores)(1993). Los Caminos de Santiago y el Territorio., Congreso Internacional., Santiago de Compostela., Xunta de Galicia., 962 págs.

THEDIECK, R., (1963), "Vers Une Politique Industrielle", L'Observateur de l'O.C.D.E., N5, Agosto, París.

THERBON, J. (1989): «Los retos del Estado de Bienestar: la contrarrevolución que fracasa, las causas del malestar y la economía política de las presiones de cambio»».

TRÍAS, E. (1998), Entre el casino global y el santuario local., El Mundo., 1 de septiembre.

UNITED NATIONS (2000): Human Development Report 2001. Oxford University Press.

UNITED NATIONS (2000): Global Outlook 2001. An Economic Social and Environmental Perspective. New York.

VÁZQUEZ, C. (1996). Urbanización y movilidad en el Randstad holandés., Madrid., $\mathrm{M}^{\mathrm{o}}$ Fomento.

VENCE, X Y OUTES, X.L. (1998). La Unión Europea y la crisis del Estado del Bienestar., Madrid., Edt. Síntesis., 429 págs.

VÁZQUEZ BARQUERO., A. (1993). Politica económica local., Madrid., Edt. Pirámide., 333 págs.

VERCHER, A., (1998), "Derechos Humanos y Medio Ambiente", Claves de Razón Práctica, $N^{\circ}$ 84, Julio-Agosto, Madrid.

VILLAMIL SERRANO, A., MATÍES GARCÍA, J., (1998), Politica Económica del Medio Ambiente, Aplicaciones Empresariales, Colección Ceura, Editorial Centro de Estudios Ramón Areces, Madrid.

VV.AA. (1990): Economía de la pobreza. I.C.E. N.686.

VV.AA. (1991): Desarrollo Humano: informe de 1991. Bogotá. PNUD. Tercer Mundo Editores.

VV.AA. (1992): «Guía de acción joven sobre desarrollo sostenible». Madrid. AIESEC. 280 págs.

VAN DE WALLE, N. (1989): «Privatization in developing countries: a review of the issues». World Development, 1(5). pp. 601-615.

VAZQUEZ BARQUERO, A. (1998). "Desarrollo local y dinámica regional, las enseñanzas de las experiencias españolas"., en Mella, J.Mª (coord.). Economía y política regional en España ante la Europa del siglo XXI., Madrid., Edcs. Akal., pp. 60-72.

VIDAL, J.M. (1990): Hacia una economía mundial Norte-Sur:frente afrente. Barcelona.Plaza \& Janes-Cambio 16. 410 págs.

VILÁ VALENTÍ, J. (1980). "El concepto de región”., en AA.VV. La región y la Geografia Española., Valladolid., pp. 13/51.

VILAGRASA, J. (1991). "Conceptos clave y filofofía de la ciencia en geografía"., en Anales de Geografía de la U.C.M., n 11., pp. 49/80. 
VIDAL, D. (1998). “¿Desarrollo o regresión en el Sur?, Le Monde diplomatique., octubre. VELTZ, P (1999). Mundialización, ciudades y territorios., Barcelona., Adt. Ariel. WOODS, R. (1982): Population analysis in geography. London. Longman. 245 págs. 